\title{
Graphene and Graphene-Like Materials for Hydrogen Energy
}

\author{
O. K. Alekseeva ${ }^{a}$, I. V. Pushkareva ${ }^{a} *$, A. S. Pushkarev ${ }^{a}$, and V. N. Fateev ${ }^{a}$ \\ ${ }^{a}$ National Research Center Kurchatov Institute, Moscow, Russia \\ *e-mail: pushkareva_iv@nrcki.ru
}

Received June 10, 2020; revised June 10, 2020; accepted June 22, 2020

\begin{abstract}
The review is devoted to current and promising areas of application of graphene and materials based on it for generating environmentally friendly hydrogen energy. Analysis of the results of theoretical and experimental studies of hydrogen accumulation in graphene materials confirms the possibility of creating on their basis systems for reversible hydrogen storage, which combine high capacity, stability, and the possibility of rapid hydrogen evolution under conditions acceptable for practical use. Recent advances in the development of chemically and heat-resistant graphene-based membrane materials make it possible to create new gas separation membranes that provide high permeability and selectivity and are promising for hydrogen purification in processes of its production from natural gas. The characteristics of polymer membranes that are currently used in industry for the most part can be significantly improved with small additions of graphene materials. The use of graphene-like materials as a support of nanoparticles or as functional additives in the composition of the electrocatalytic layer in polymer electrolyte membrane fuel cells makes it possible to improve their characteristics and to increase the activity and stability of the electrocatalyst in the reaction of oxygen evolution.
\end{abstract}

DOI: $10.1134 / \mathrm{S} 1995078020030027$

\section{TABLE OF CONTENTS}

Introduction

1. Graphene-based hydrogen storage systems

2. Graphene-based membranes for purification and concentration of hydrogen

3. Application of graphene in electrocatalytic layers of polymer electrolyte membrane fuel cells

Conclusions

\section{INTRODUCTION}

In recent years, graphene has received much attention from the scientific community. The innovative experiments of A.K. Geim and K.S. Novoselov, for which they were awarded the Nobel Prize in Physics in 2010 [1], gave a huge boost to the active research and implementation of graphene and graphene-like materials in various fields of science and technology. Graphene is a single layer (monolayer) of carbon atoms strongly bound in a hexagonal crystal lattice. This is a carbon allotrope in the form of a plane of $s p^{2}$ bonded carbon atoms with a molecular bond length of $0.142 \mathrm{~nm}$ [2]. Graphene possesses a number of unique properties, such as very high thermal and electrical conductivities and high specific surface area, mechanical strength, and resistance against corrosive environments [2, 3]. All of these properties make it an extremely promising material for use in nanoelectronics and electrochemical power engineering, and in the field of membrane materials for desalination and water purification; research on the anti-cancer properties of graphene is also underway. This review considers new topical and promising areas of application of graphene and materials based on it for generating environmentally friendly hydrogen energy, namely, in hydrogen purification and storage systems, as well as in electrochemical systems for the production and utilization of hydrogen.

\section{GRAPHENE-BASED HYDROGEN STORAGE SYSTEMS}

For the development of hydrogen power generation, it is necessary to create safe and efficient systems for the reversible storage of hydrogen with high capacity and stability, and the possibility of rapid hydrogen evolution [4-8]. Much attention has been paid to graphene-based nanomaterials, two-dimensional (2D) crystals composed of a monolayer of $s p^{2}$ hybridized carbon atoms that form a honeycomb structure. This configuration of carbon atoms can provide effective bonding with hydrogen atoms. In terms of hydrogen storage, graphene has other useful properties as well. It is an environmentally friendly, lightweight, and thermally and chemically stable material, which has 
high mechanical strength and can be transported over long distances. At the same time, graphene is a flexible material, which is important for use in various devices. Graphene can be synthesized in large quantities using different methods, and its production is becoming cheaper every year. According to theoretical estimates, the specific surface area of graphene is $2630 \mathrm{~m}^{2} / \mathrm{g}$ $[9,10]$. Indeed, individual sheets obtained during the synthesis of graphene form agglomerates and/or have defects, so the real specific surface is usually $150-$ $600 \mathrm{~m}^{2} / \mathrm{g}$ (less often about $2000 \mathrm{~m}^{2} / \mathrm{g}$ ). It should be noted that the specific surface area of three-dimensional (3D) graphene materials can reach $3500 \mathrm{~m}^{2} / \mathrm{g}$ $[11,12]$. These materials will be discussed separately below.

Hydrogen can be adsorbed on graphene in two ways. These are physical sorption (usually hydrogen in molecular form) and chemisorption (atomic hydrogen).

The physical sorption is caused by physical interactions mainly due to van der Waals forces. This process shows fast kinetics, but high pressures and low temperatures are required to ensure stability. According to various estimates, the binding energy at a distance of about $0.3 \mathrm{~nm}$ from the graphene layer is only $0.01-$ $0.06 \mathrm{eV}[13,14]$. The first theoretical estimates of the gravimetric hydrogen storage capacity of graphene gave very low values, but the authors of [15] in 2005 took into account quantum effects in their model and obtained encouraging results. It should be noted that we are not talking about a separate graphene sheet. The above study presents data for two graphene layers separated by an interlayer gap of $d=0.4-1.4 \mathrm{~nm}$ (Fig. 1). The calculations were performed for pressures of 5 and $10 \mathrm{MPa}$ and temperatures in the range of 200-300 K. The best results were obtained for an interlayer distance of about $0.7 \mathrm{~nm}$ (in natural graphite, the distance between layers is about $0.335 \mathrm{~nm}$ ). The gravimetric capacity at a temperature of $300 \mathrm{~K}$ and at pressures of 5 and $10 \mathrm{MPa}$ is 3.32 and $4.54 \mathrm{wt} \%$, respectively; this characteristic at $250 \mathrm{~K}$ and at pressures of 5 and $10 \mathrm{MPa}$ is 5.11 and $6.43 \mathrm{wt} \%$, respectively. A substantial decrease in the gravimetric capacity values is observed for interlayer distances of less than $0.6 \mathrm{~nm}$ and more than $0.8 \mathrm{~nm}$. According to the authors of [15], only a system of layers with an increased distance compared to that of graphite can be of interest for practical application. Such systems can be created, for example, by introducing other atoms (this topic will be have more discussion below).

In most experiments, the values of the sorption capacity of graphene turned out to be rather low, in particular, less than $1 \mathrm{wt} \%$ at room temperature and pressures of $0.1-10 \mathrm{MPa}$ and slightly more than $1 \mathrm{wt} \%$ at $77 \mathrm{~K}$ (for example, see [14, 16, 17]). Some of the best experimental data on sorption capacity were obtained in [18], namely, $3.1 \mathrm{wt} \%$ at $300 \mathrm{~K}$ and $10 \mathrm{MPa}$. A graphene sample with a specific surface area of
$925 \mathrm{~m}^{2} / \mathrm{g}$ was obtained by exfoliation of graphite oxide and consisted of 3-6 layers (Fig. 2). The value of the gravimetric capacity was close to the calculated one [15]; however, it should be taken into account that the authors of [18] do not exclude the presence of functional groups that have arisen during synthesis and processing.

The authors of [19] used a modified version of the expanded graphite model and demonstrated the possibility of storing hydrogen between layers of graphene nanoplates. Experiments have confirmed their conclusions about marked physical sorption. The gravimetric capacity of such a system at a pressure of $0.2 \mathrm{MPa}$ and a temperature of $99 \mathrm{~K}$ was $2.47 \mathrm{wt} \%$.

Graphene with nanoblisters deserves separate mention. This structure is a graphene layer with islets of various shapes, in which gas can accumulate. Blistering, which is among the most dangerous mechanisms of destruction of metals due to the formation of bubbles filled with gas (hydrogen, helium, etc.), has been actively studied for more than 50 years, especially in connection with the problem of creating a thermonuclear reactor [20]. In contrast, the blister structure found in graphene materials can be used for the development of hydrogen storage and transportation systems [21-23]. Blisters of different sizes appear during the synthesis of graphene materials or are specially formed to obtain certain electronic properties [24]. Under the influence of atomic hydrogen, such structures are formed on the surface of highly oriented pyrolytic graphite (HOPG) or graphene [21-23]. In [21], HOPG samples were exposed to atomic hydrogen $\left(5 \times 10^{13} \mathrm{~N} / \mathrm{cm}^{2}\right)$. As a result, the surface of the samples was covered with lumps, in which molecular hydrogen was detected by various methods, including the method of scanning electron microscopy (SEM), and its pressure was estimated to be about 2.7 MPa. The blisters were stable for several months. The author of [21] believed that there had been intercalation of the atomic hydrogen, which is small enough to penetrate into the graphite layers. It then turned into molecular hydrogen gas, deformed a layer of graphite (graphene), and was trapped in a blister. In [23], the sorption of hydrogen into a system of several graphene layers with blisters in the upper monolayer was studied (Fig. 3). In accordance with the experimental results published in [21], the filling with atomic hydrogen was considered. Simulation showed that the maximum hydrogen density in a blister about $7 \mathrm{~nm}$ in size at $77 \mathrm{~K}$ and normal pressure is $6.86 \mathrm{wt} \%$; moreover, $6.66 \mathrm{wt} \%$ is attributed to the fraction of molecular hydrogen and only $0.2 \mathrm{wt} \%$ remains in the form of atoms that have formed chemical bonds with the lattice at the blister periphery. Blisters are mechanically stable even in the presence of defects in the structure, but hydrogen can be released with an increase in the temperature or pressure. Indeed, the prospects for practical application are not yet clear, but it was difficult to imag- 

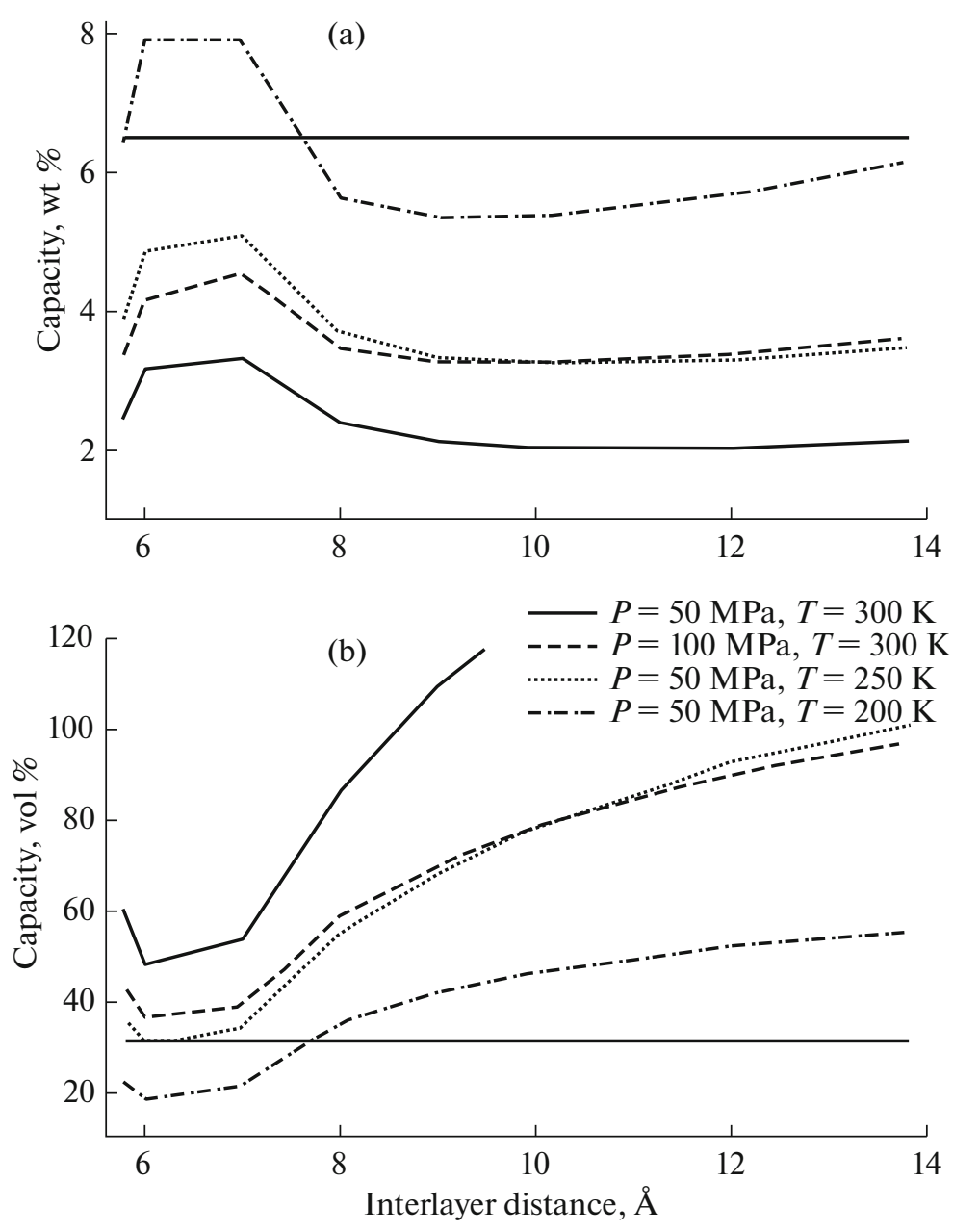

Fig. 1. Dependences of (a) gravimetric and (b) volumetric hydrogen storage capacities on interlayer distance. The solid horizontal lines at $6.5 \mathrm{wt} \%$ and $31.2 \mathrm{~cm}^{3} / \mathrm{mol}$ are the benchmarks for hydrogen storage on board vehicles [15].

ine a few years ago that graphene blisters would be used in the development of various nanomechanical devices [23].

The volumetric storage capacity of hydrogen during physical sorption in graphene materials depends on the degree of compaction of graphene flake plates. Sufficient values can be achieved at room temperature and a pressure of $10 \mathrm{MPa}$ [15].

During chemisorption (chemical adsorption) of hydrogen, a chemical bond (mostly of covalent nature) is formed between hydrogen and graphene atoms. The hybridization of carbon atoms changes from the $s p^{2}$ type to the $s p^{3}$ type. For the chemisorption of molecular hydrogen, dissociation (dissociative chemisorption) is required. Chemisorption of atomic hydrogen is a more favorable process. It is believed that the binding energy and the barrier of chemisorption for atomic hydrogen are around 0.7 and $0.3 \mathrm{eV}$, respectively [13]. However, this raises the issue of the reversibility of the adsorption process.

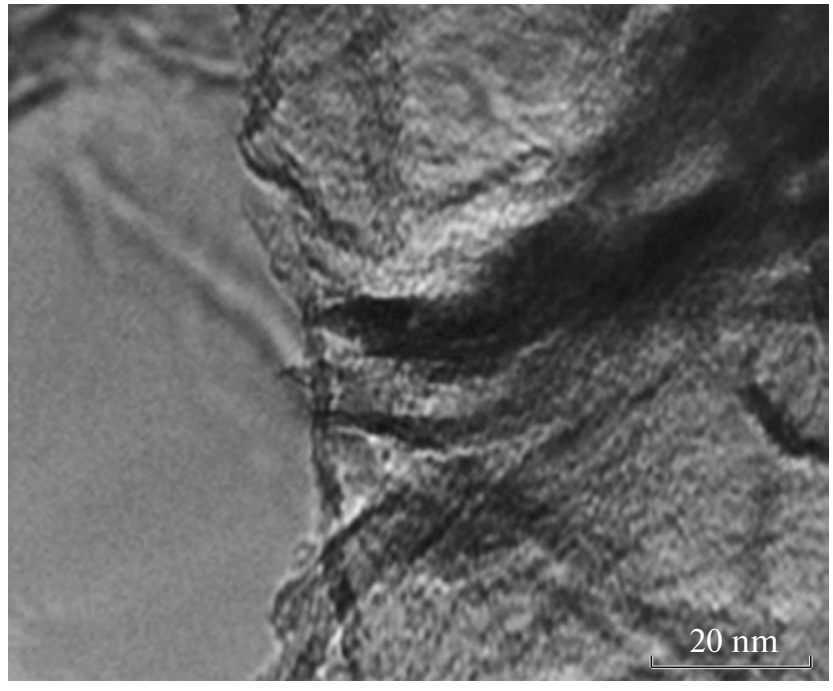

Fig. 2. Image of graphene synthesized by thermal exfoliation of graphite oxide [18]. 
(a)

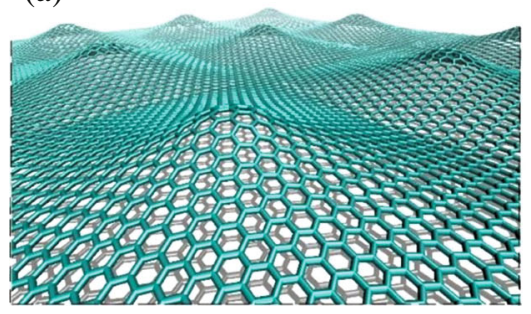

(b)

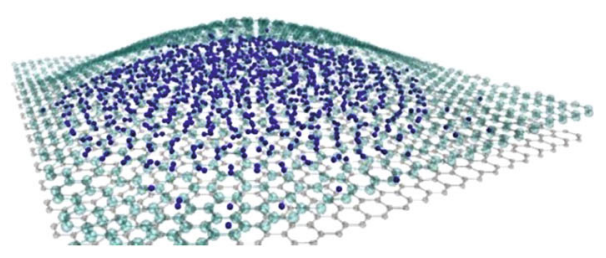

Fig. 3. (Color online) (a) Graphene with nanoblisters; (b) blister filled with hydrogen (6.86 wt \%) [23].

During chemisorption, the maximum attainable sorption capacity corresponding to the filled graphene surface is $8.3 \%(1: 12)$. For hydrogen power engineering, hydrogenated graphene, or graphene, is also of interest from the point of view of hydrogen storage. Graphane is a 2D material in which each carbon atom is bonded to a hydrogen atom and three carbon atoms. In 2003, the authors of [25] theoretically considered the possibility of chemisorption of hydrogen on both sides of a graphene sheet. The material was named graphane in 2006 by the authors of [26], who demonstrated, using the first principles calculations, its stability at room temperature. In 2009, graphane was experimentally obtained [27]; its structure is shown in Fig. 4.

To ensure the chemisorption of hydrogen on both sides, the authors of [27] used graphene samples in the form of free membranes. The treatment was carried out with cold hydrogen plasma. It should be noted that desorption is a problem for hydrogen storage systems in this case as well.

As can be seen from the above, ideal graphene (as well as graphane) is not a promising material for practical hydrogen storage. Let us consider in more detail the main directions of experimental and theoretical studies to increase sorption capacity and enhance the kinetics of hydrogen sorption/desorption on graphene.

Study of the effects of the surface curvature of graphene materials on the chemisorption of hydrogen is among these directions [14, 28-30]. The density
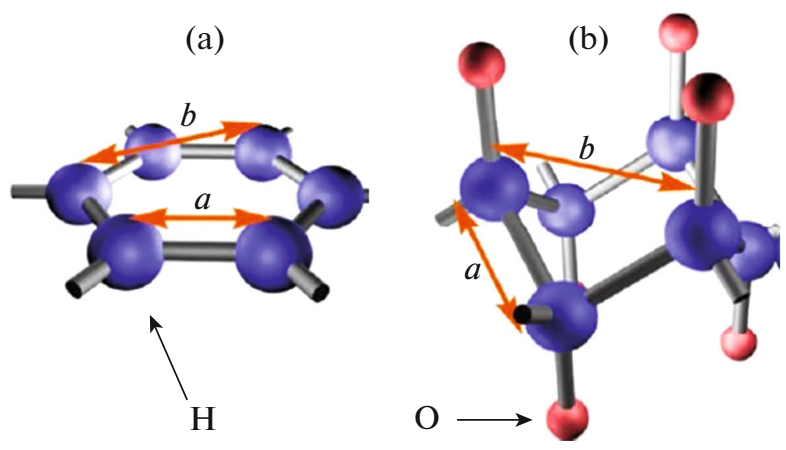

Fig. 4. (Color online) Crystal structures of (a) graphene and (b) graphane [27]. functional theory calculations demonstrated the dependence of the binding energy and the adsorption barrier on the surface curvature. The binding energy on convex surfaces-for example, on the ridges of corrugated graphene-is $1-2 \mathrm{eV}$ higher than in the valleys $[28,29]$, and the adsorption barrier is substantially reduced. Experimental results obtained using scanning tunneling microscopy confirmed these conclusions [30]. The authors of [30] studied the adsorption of hydrogen and found atomic hydrogen precisely on the convex regions of the graphene monolayer. The curvature of graphene was caused by an interaction with the $\mathrm{SiC}$ (0001) substrate (it should be noted that there are other methods of preparation of corrugated, folded, and other types of graphene; for example, see [31]). Calculations showed that curvature inversion is required for hydrogen desorption (Fig. 5).

Curvature inversion gives rise to desorption of hydrogen in the molecular form [28].

The dependence of chemisorption on the surface curvature in combination with the flexibility of
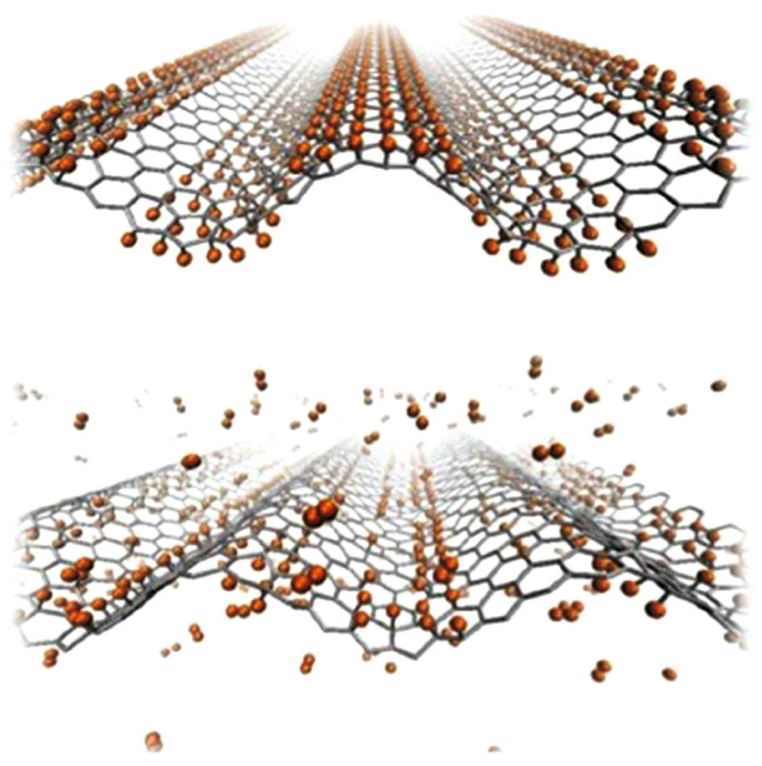

Fig. 5. (Color online) Atomic hydrogen is adsorbed on the surface ridges. Inversion of the curvature results in desorption of molecular hydrogen [28]. 


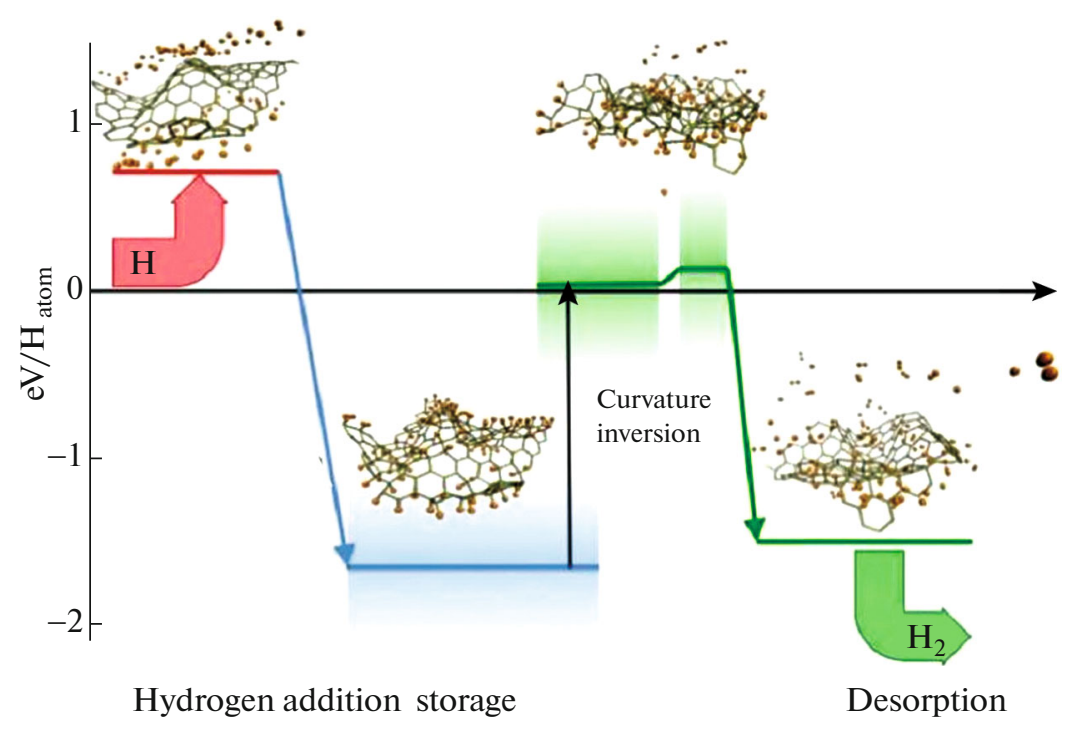

Fig. 6. (Color online) Diagram of a hydrogen storage device. Three phases can be distinguished. Atomic hydrogen is supplied into the device and chemisorbed on the protrusions (ridges), i.e., the storage stage begins. Inversion of the curvature leads to associative desorption of $\mathrm{H}_{2}[29]$.

graphene gives hope for the creation of reversible hydrogen storage systems with controlled hydrogen evolution at room temperature. According to the authors of [29], the gravimetric capacity can reach $8 \mathrm{wt} \%$. Associative desorption of hydrogen occurs with curvature inversion, for example, under the influence of external fields, without changing the temperature and pressure (Fig. 6).

For practical application, it is important that folds and waves that are nearly always present on the graphene surface are chemically active regions and can reduce, as the density functional theory calculations show [32], the dissociation energy of molecular hydrogen by a factor of 6 . The authors of [33] demonstrated in their experiments that hydrogen, unlike all other gases, penetrates through a graphene monolayer. It is the presence of regions with local curvature and stressed state, on which adsorption and dissociation of molecular hydrogen take place (the barrier for reaching this state is reduced to $1 \mathrm{eV}$ ), that causes this. An $s p^{3}$ bond is formed. Hydrogen atoms that penetrate through the graphene monolayer are desorbed from the concave surface, which allowed the authors of [33] to detect them.

This line of research relates to a change in the configuration of the graphene surface, and practical applications require creation of three-dimensional systems that would retain, if possible, the necessary properties during the transition from $2 \mathrm{D}$ to $3 \mathrm{D}$ structures. It is very difficult to pack graphene sheets into a multilayer 3D structure while maintaining a distance of about $0.7 \mathrm{~nm}$ between them, which is optimal for physical sorption [15, 34]. At present, researchers mainly use the two approaches: the creation of disordered porous frameworks and the incorporation of molecular columnar spacers between the graphene sheets $[9,11$, 12]. The precursors in both versions are graphene flakes or reduced graphene oxide (RGO) flakes. Unlike graphene, reduced graphene oxide contains residual oxygen and other heteroatoms, as well as structural defects. Reduced graphene oxide is obtained from graphene oxide (GO) by ultrasonic, chemical or thermal reduction, as well as from graphite oxide after preliminary reduction of this material with alkalis to GO. The authors of [11] used RGO flakes obtained from graphite oxide and additionally activated in $\mathrm{KOH}$ in their experiments. As a result, a hierarchical three-dimensional framework structure (3D scaffolds) was formed from particles up to $10 \mu \mathrm{m}$ in size, which consisted of defective and interconnected graphene layers (Fig. 7). The specific surface area and pore volume were $3200-3400 \mathrm{~m}^{2} / \mathrm{g}$ and $2.2 \mathrm{~cm}^{3} / \mathrm{g}$, respectively. The gravimetric capacity at $77 \mathrm{~K}$ reached a maximum under a pressure of $4 \mathrm{MPa}$ and was $7.04 \mathrm{wt} \%$; the sorption of hydrogen at 193 and $296 \mathrm{~K}$ increased with an increase in the pressure and was 4 and $1.13 \mathrm{wt} \%$ under a pressure of $12 \mathrm{MPa}$ for 193 and $296 \mathrm{~K}$, respectively (Fig. 7). Additional activation in a hydrogen atmosphere for $2 \mathrm{~h}$ at $450^{\circ} \mathrm{C}$ increased the sorption of hydrogen by about $10 \mathrm{wt} \%$ for all three temperatures.

In the second version of the formation of $3 \mathrm{D}$ graphene structures, molecular columns composed of organic molecules-for example, polyaniline and diamines-are often used to separate layers (Fig. 8) [35]. Simulation gives good results of about $4 \mathrm{wt} \%$, but the gravimetric capacity in various experiments reaches only $1.5 \mathrm{wt} \%$ [12].

Researchers also propose more exotic versions, in which carbon nanotubes (CNTs) [36, 37] or fullerenes 
(a)
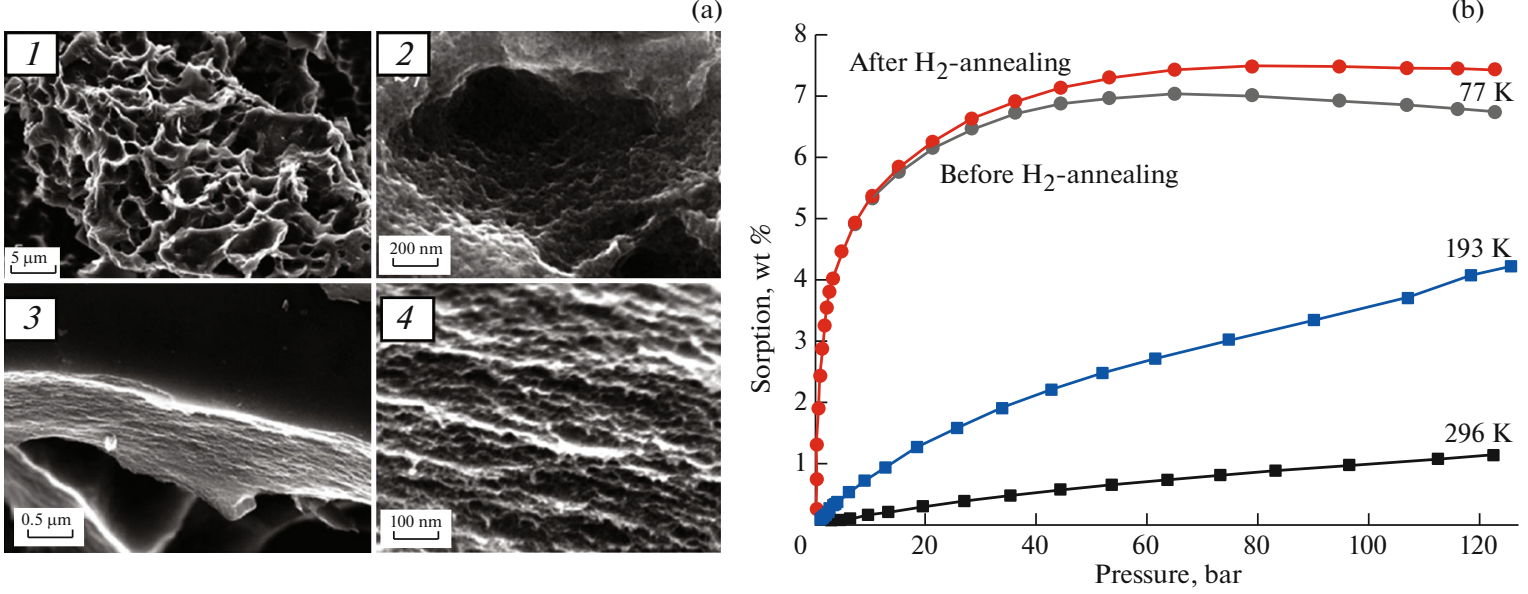

Fig. 7. (Color online) (a) SEM images of a sample with a BET specific surface area of about $3300 \mathrm{~m}^{2} / \mathrm{g}$. A hierarchical porous structure $(1,2)$ and a layered structure at the microparticle edges $(3,4)$ are visible. (b) Adsorption isotherms of a sample with a specific surface area of $3230 \mathrm{~m}^{2} / \mathrm{g}$ at 77 (before and after annealing in hydrogen), 193, and $296 \mathrm{~K}$ [11].

(Fig. 9) serve as supporting pillars between graphene overlays [38]. First, the results of computer simulation of such systems appeared, in which quite good hydrogen sorption parameters were predicted (for example, 4 wt $\%$ at $77 \mathrm{~K}$ and $1 \mathrm{MPa}$ and $6.1 \mathrm{wt} \%$ and $41 \mathrm{~g} / \mathrm{L}$ under normal conditions with the addition of $\mathrm{Li}$, according to [36]). Later, 3D systems with columns of nanotubes were synthesized, but by rather complicated methods [37, 39], and it is difficult to imagine the possibility of their practical application.

The authors of the studies described above were looking for opportunities to increase the sorption capacity and improve the kinetics of hydrogen sorption and desorption on graphene materials by changing the surface curvature, increasing the distance between layers, and creating 3D framework systems. The results of theoretical calculations and simulations are quite optimistic, but it was not possible to achieve the required sorption capacity values at temperatures

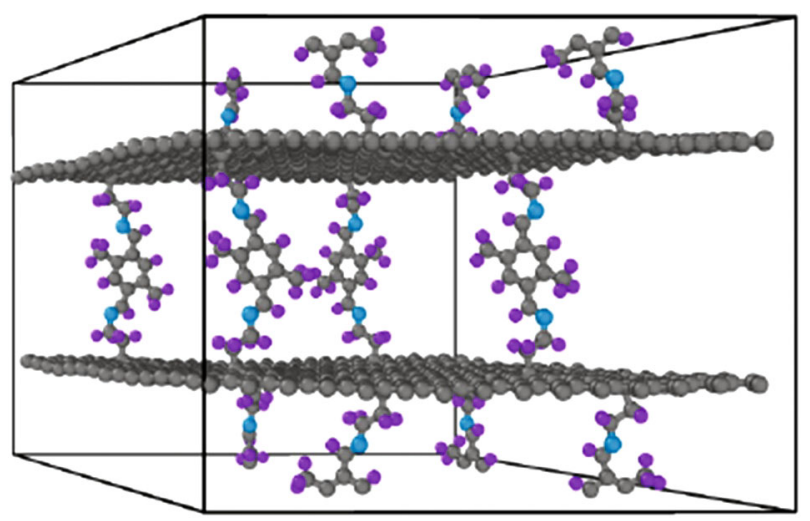

Fig. 8. (Color online) Three-dimensional diagram of a graphene structure with columns of organic molecules [35]. and pressures acceptable for practical use in experiments, both in cases of physical sorption and chemisorption. Perhaps this is because the synthesized samples cannot fully reproduce the ideal model systems.

The functionalization of graphene with heteroatoms is another approach aimed at increasing the sorption of hydrogen under normal conditions [13, 14, 17, 40-43]. This includes the addition of alkaline metal atoms $(\mathrm{Li}, \mathrm{Na})[44,45]$ and transition metals $\mathrm{Ti}, \mathrm{Ni}$, $\mathrm{Pd}, \mathrm{Pt}$ to the graphene surface (so-called decoration) $[16,46,47]$, the substitution of carbon atoms in graphene with B, S, N, P (doping) [48, 49], and simultaneous decoration and doping [17, 40, 50, 51]. Transition metal atoms on the graphene surface act as catalytic centers for the dissociative chemisorption of hydrogen. A spillover effect, i.e., migration of the formed hydrogen atoms onto graphene, occurs because of their presence, which increases the sorption efficiency $[6,9,52]$. In addition, researchers who follow this line of research believe that the decorated or doped systems will eliminate the drawbacks of both chemical and physical sorption and provide intermediate values of the binding energy. This will allow one to improve both the stability of the system and the kinetics of sorption/desorption even at room temperature. We will give some of the results of theoretical and experimental studies. An example of the effective action of $\mathrm{Li}$ additives to a 3D graphene system with CNT pillars has been discussed above [36]. Theoretical studies [44] showed that the gravimetric density of the graphene-2 $\left(\mathrm{Li}-3 \mathrm{H}_{2}\right)$ system can reach $10.2 \mathrm{wt} \%$. The authors considered the graphene-2Li-graphene structure (two layers of graphene with lithium atoms in the gap, which decorate the layers called floor and ceiling) (Fig. 10). The average energy of adsorption of $\mathrm{H}_{2}$ molecules on the $\mathrm{Li}$ atom is $0.37,0.17$, and $0.12 \mathrm{eV}$ 

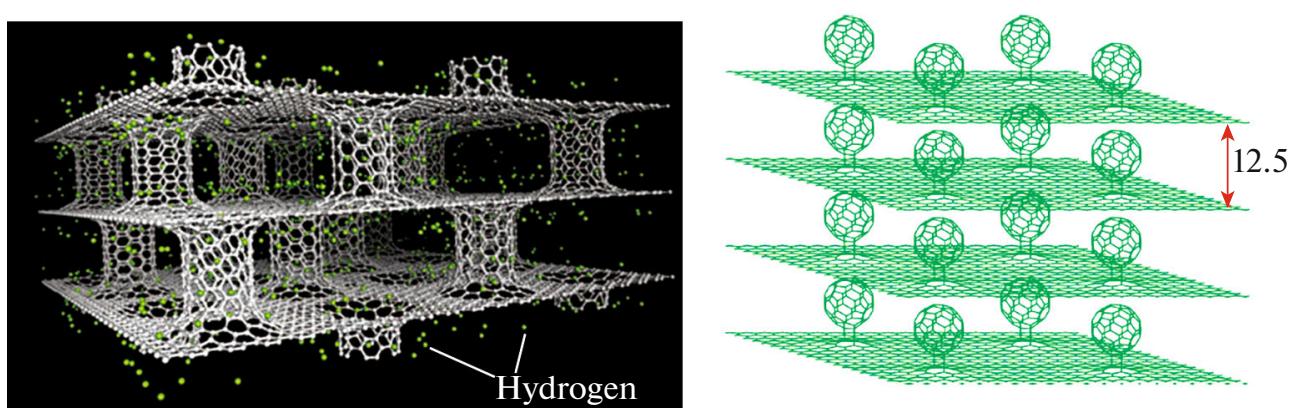

Fig. 9. (Color online) Graphene 3D-systems with carbon nanotubes [36] and fullerenes [38].
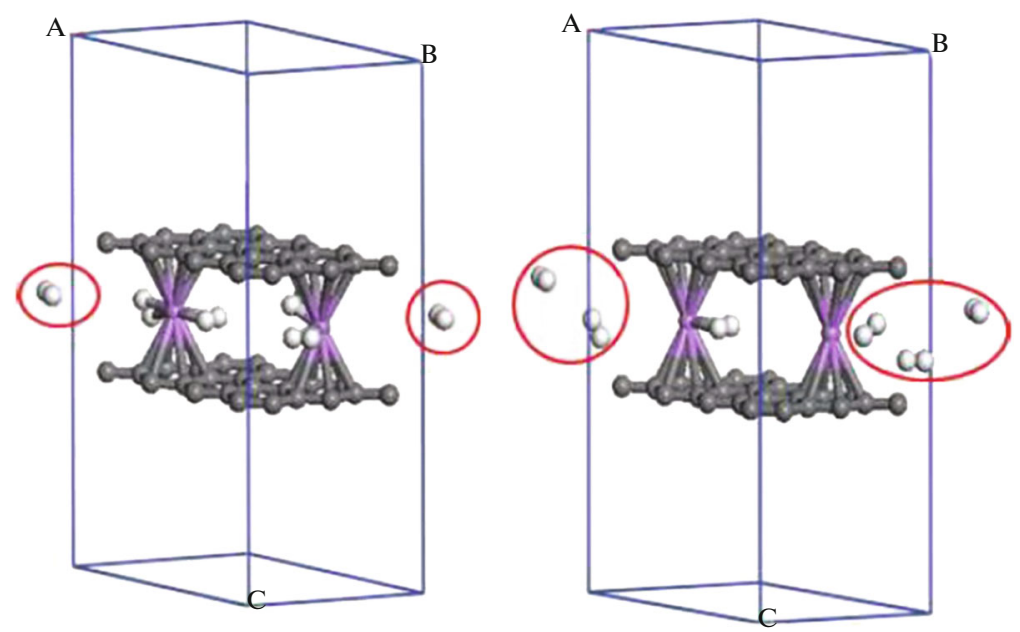

Fig. 10. (Color online) Graphene-2( $\left.\mathrm{Li}-3 \mathrm{H}_{2}\right)$-graphene structure after 5 ps annealing at 77 and $300 \mathrm{~K}$ [44].

for hydrogen molecules $1-3$, respectively; these values are between the values for physical and chemical sorption $(0.06-0.8 \mathrm{eV})$. Thus, the reversible adsorption of hydrogen can be achieved.

The first principles calculations for graphene decorated with $\mathrm{Ca}$ atoms showed that up to six hydrogen molecules can be adsorbed on a $\mathrm{Ca}$ atom with a binding energy of $0.2 \mathrm{eV} / \mathrm{H}_{2}$, while the gravimetric capacity can reach about 5 wt \% (Fig. 11) [53].

As was shown by the results of theoretical estimates and simulation, as well as by the results of experiments, the decoration with transition metals leads to the formation of stable, but reversible systems. Ab initio calculations with the use of the density functional theory demonstrated that the adsorption of $\mathrm{Pt}$ atoms leads to an increase in the binding energy of hydrogen molecules in comparison with the value for the initial graphene, which is around $0.07 \mathrm{eV}$ [47]. Depending on the number of adsorbed hydrogen molecules, which can vary in the range from one to eight, the binding energy varies from 1.84 to $0.13 \mathrm{eV}$, respectively. The gravimetric capacity of graphene for the adsorption of eight $\mathrm{H}_{2}$ molecules per Pt atom is $3.74 \mathrm{wt} \%$. Experimental data confirm that the gravimetric capacity of graphene increases upon decoration with transition metals, but the values do not exceed $1.5 \mathrm{wt} \%[16,46$, 54]. Thus, the authors of [54] obtained $1.4 \mathrm{wt} \%$ at $298 \mathrm{~K}$ under a pressure of $3 \mathrm{MPa}$ after decorating a sample of graphene plates comprising several layers with platinum. In [46], the decoration with Pt and Pd

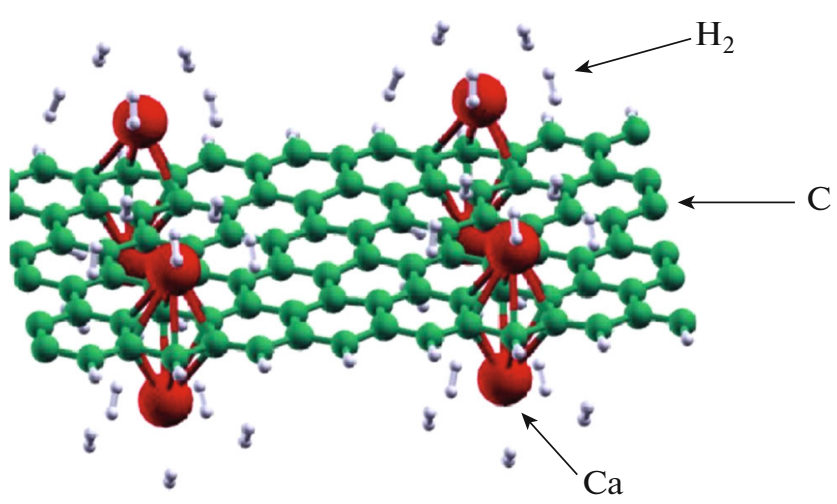

Fig. 11. (Color online) Optimized structure of graphene with $\mathrm{Ca}$ atoms, which adsorbs the maximum number of hydrogen molecules [53]. 
(a)
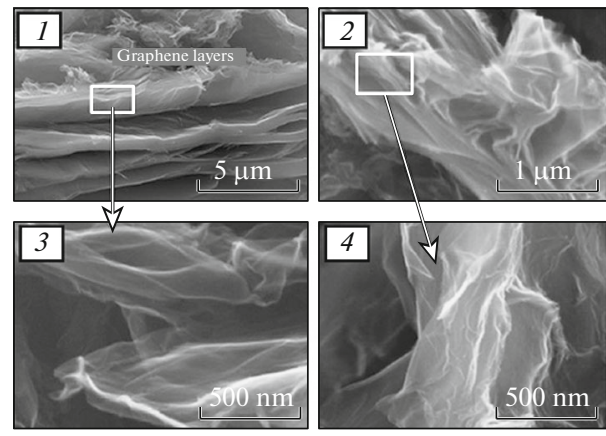

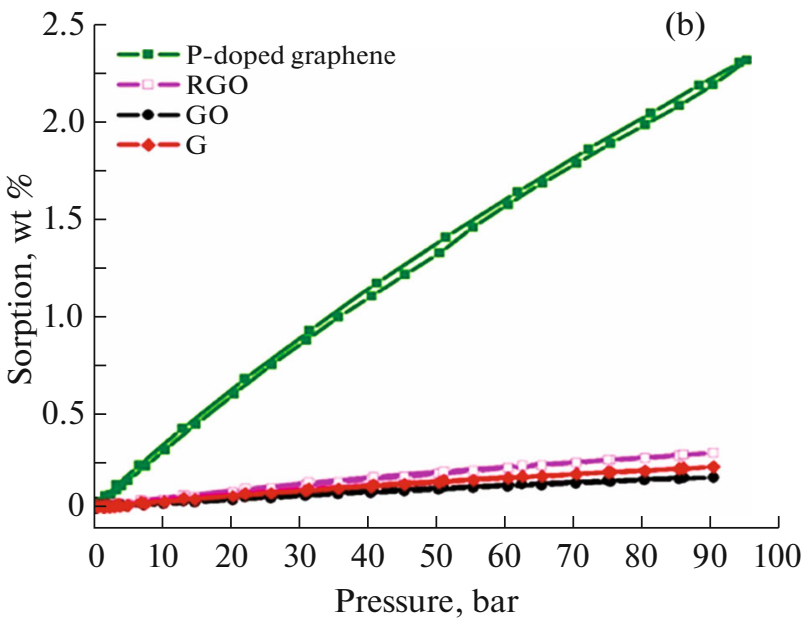

Fig. 12. (Color online) (a) SEM images of a material made of multilayer graphene sheets doped with phosphorus. (b) Sorption of hydrogen by this material, undoped graphite powder $(\mathrm{G})$, graphene oxide $(\mathrm{GO})$, and reduced graphene oxide (RGO) [49].

(a)

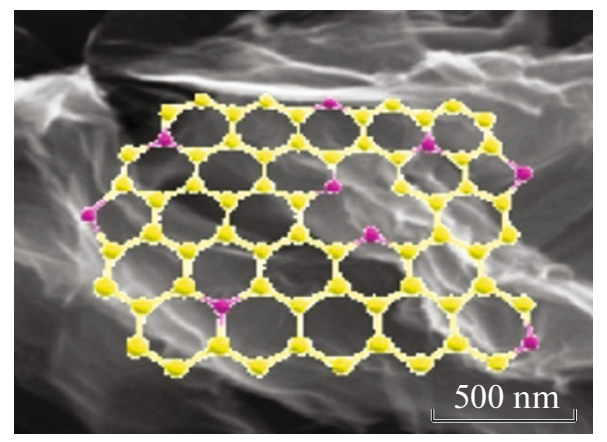

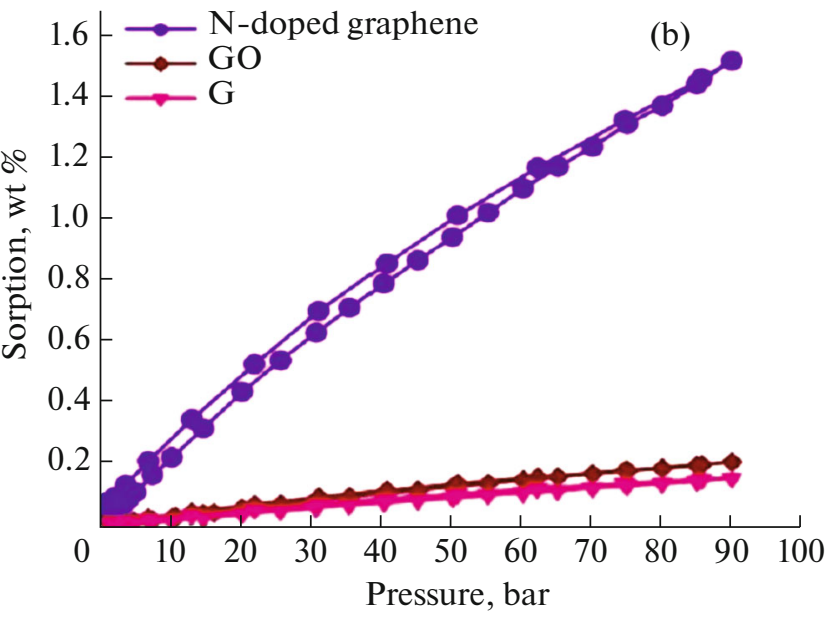

Fig. 13. (Color online) (a) Nitrogen-doped graphene material and (b) adsorption/desorption isotherms of this material, undoped graphite powder $(\mathrm{G})$, and graphite oxide (GO) at $298 \mathrm{~K}$ [48].

led to a twofold increase in the sorption capacity of graphene at $303 \mathrm{~K}$ and $5.7 \mathrm{MPa}$ from 0.067 to 0.15 and $0.156 \mathrm{wt} \%$, respectively. It is possible that the spillover effect, which should promote an increase in the sorption capacity, is suppressed during particle agglomeration. The only exception seems to be excellent results obtained in [55]. The authors of [55] synthesized the Pd-graphene nanocomposite. Spherical Pd nanoparticles with sizes in the range of 5-45 $\mathrm{nm}$ were uniformly distributed over a graphene matrix consisting of graphene plates with a wrinkled surface. The gravimetric capacity reached $6.7 \mathrm{wt} \%$ for the nanocomposite with $1 \% \mathrm{Pd}$ at room temperature and under a pressure of $5 \mathrm{MPa}, 8.67 \mathrm{wt} \%$ with $1 \% \mathrm{Pd}$ under a pressure of $6 \mathrm{MPa}$, and $7.16 \mathrm{wt} \%$ in the nanocomposite.

Doping (substitution of carbon in the lattice) with $\mathrm{N}, \mathrm{P}, \mathrm{S}$, and some other atoms leads, depending on the dopant properties, to redistribution of charges at neighboring atoms, structural deformation, and the formation of vacancies. Heteroatoms can be activation centers for hydrogen that will be subsequently transferred to the surface of the carbon matrix by spillover. As was shown in [49], the gravimetric capacity of a material made of multilayer graphene sheets increases as a result of P doping and reaches about $2.2 \mathrm{wt} \%$ at $298 \mathrm{~K}$ and $10 \mathrm{MPa}$ (Fig. 12).

The layered graphene material doped with nitrogen (7.5 at \%) was studied in [48]. At room temperature and a pressure of $9 \mathrm{MPa}$, the gravimetric capacity was around $1.5 \mathrm{wt} \%$ (Fig. 13).

It should be noted that nitrogen doping is actively used in the development of efficient electrocatalysts for hydrogen fuel cells (FCs) [56-59]. Like other car- 

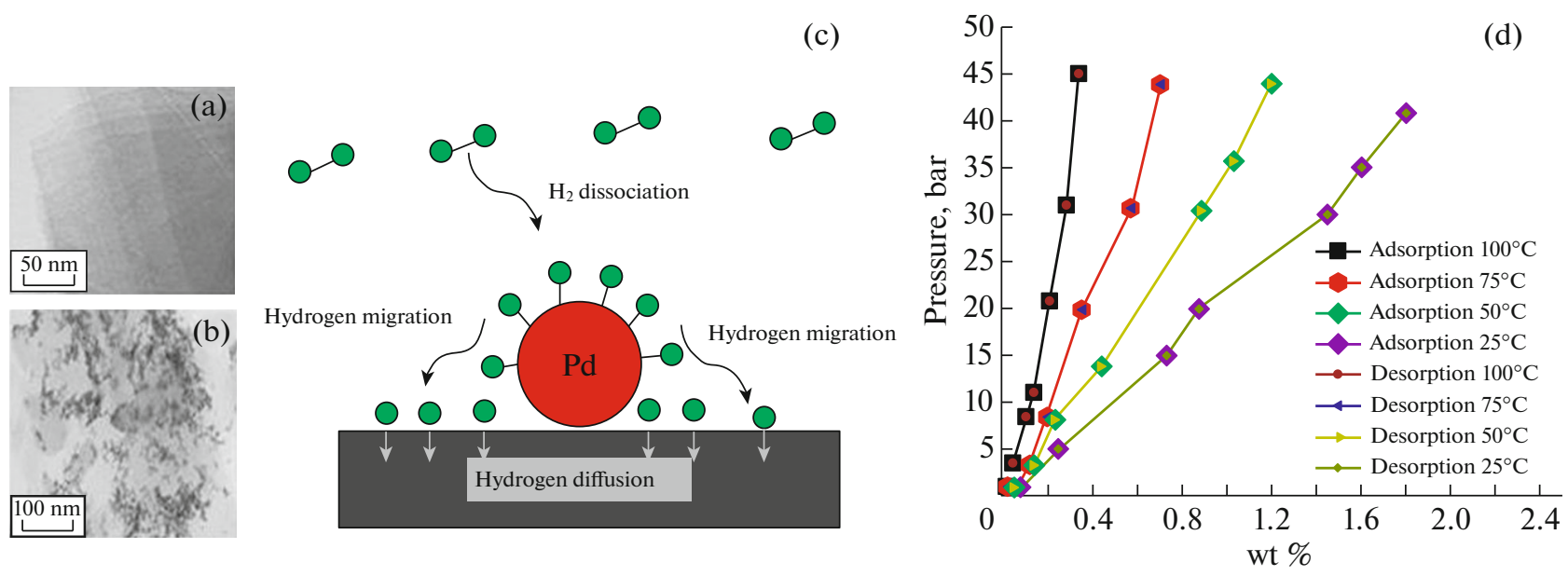

Fig. 14. (Color online) TEM images of (a) N-graphene and (b) Pd-N-graphene. (c) A schematic representation of the spillover effect on $\mathrm{Pd}-\mathrm{N}-$ graphene. (d) Adsorption-desorption isotherms of hydrogen for the sample of Pd-N-graphene at temperatures of $25-100^{\circ} \mathrm{C}$ and pressures of up to $4.5 \mathrm{MPa}$ (45 bar) [51].

bon nanomaterials, graphene itself cannot act as a catalyst due to the absence of active centers. The formation of various nitrogen configurations (graphite-like or substituting $\mathrm{N}$, pyridine $\mathrm{N}$, and pyrrole $\mathrm{N}$ configurations) leads to the creation of such centers and also plays an important role in the stabilization of catalytic metal nanoparticles ( $\mathrm{Pt}$ and $\mathrm{Pd})$. There are various methods for nitrogen doping, which are used, for example, in the synthesis of graphene materials or in their post-processing. Recent studies showed that the method of nitrogenation in gas discharge plasma is an effective method (the plasma-forming gases are nitrogen or a nitrogen/argon mixture) [60].

The most promising studies of hydrogen sorption in graphene materials with heteroatoms relate to joint decoration/doping, especially when the doping is performed with nitrogen and the decoration is performed with Pt and Pd metals. The atoms of these and some other transition metals on the graphene surface act as catalytic sites for the dissociation of hydrogen molecules. As mentioned above, the introduction of nitrogen atoms gives rise to the formation of stabilization sites for nanoparticles of these metals and prevents their agglomeration, which could reduce the spillover effect. However, there are still a surprisingly small number of experimental studies of this kind. The doping of graphene nanoplates (10-20 monatomic layers) decorated with palladium with nitrogen is an example [51]. At room temperature and a pressure of $3.2 \mathrm{MPa}$, the gravimetric capacities of graphene nanoplates, $\mathrm{N}$-doped graphene nanoplates, and $\mathrm{Pd}$-decorated $\mathrm{N}$-doped graphene nanoplates are $0.27,0.42$, and 1.25 wt \%, respectively (Fig. 14, images obtained using transmission electron microscopy (TEM)). The authors of [51] emphasize that the doping with nitro- gen provided a strong $\mathrm{Pt}$-graphene bond and a high dispersion of $\mathrm{Pt}$ nanoparticles.

To conclude of this section, we discuss another approach to creating 3D hydrogen storage systems. Graphene is not the main component in them, but it plays an important role. We are talking about composites of nanostructured hydrides wrapped in graphene [61]. Complex hydride $\mathrm{LiBH}_{4}$ has high calculated gravimetric (18.5 wt \%) and volumetric $\left(121 \mathrm{~kg} / \mathrm{m}^{3}\right)$ densities, but also the high desorption temperature [6]. Its thermodynamic parameters can be slightly improved by adding destabilizing agent $\mathrm{MgH}_{2}$. The gravimetric capacity of the $2 \mathrm{LiBH}_{4}-\mathrm{MgH}_{2}$ system is 11.4 wt \%. To achieve an acceptable desorption rate, temperatures above $400^{\circ} \mathrm{C}$ are still required. In addition, problems, such as grain growth, phase separation, and particle agglomeration, arise upon cycling. The authors of [61] created a unique composite of $2 \mathrm{LiBH}_{4}-\mathrm{MgH}_{2}$ nanoparticles with a size of about $10.5 \mathrm{~nm}$, which are uniformly distributed over graphene substrates that are flexible, but strong. The synthesis scheme is shown in Fig. 15.

The SEM images of $\mathrm{MgH}_{2}$ nanoparticles on graphene and $2 \mathrm{LiBH}_{4}-\mathrm{MgH}_{2}$ nanoparticles on graphene are shown in Fig. 16.

The nanocomposite has a high hydrogen sorption capacity (9.1 wt \%) and good stability during cycling (the capacity after 25 cycles at $350^{\circ} \mathrm{C}$ is $8.9 \mathrm{wt} \%$ ).

The results of theoretical and experimental studies of hydrogen accumulation in graphene materials considered above confirm the possibility of creating effective systems for reversible hydrogen storage on their basis. 


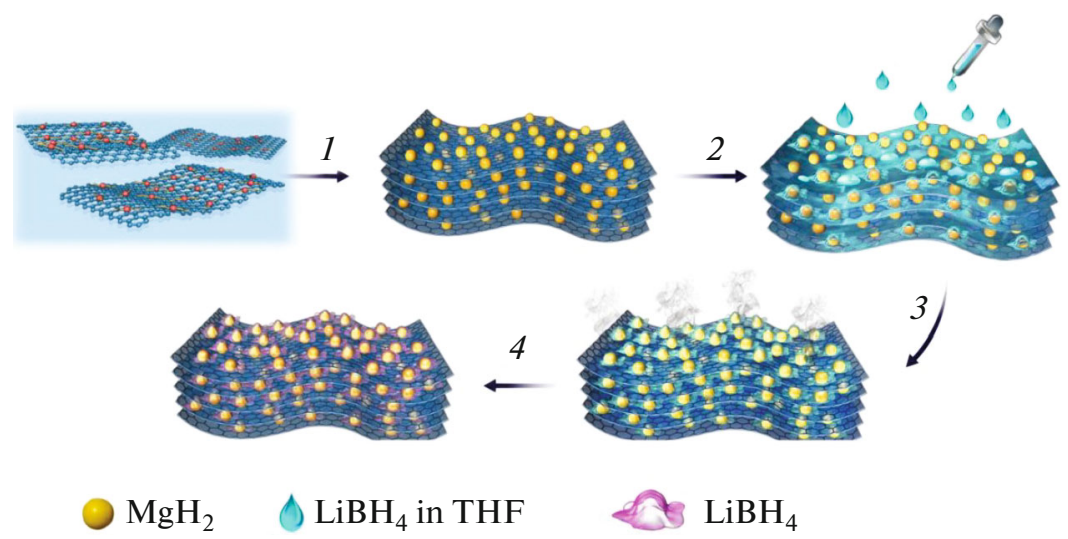

Fig. 15. (Color online) Scheme of the synthesis of the $2 \mathrm{LiBH}_{4}-\mathrm{MgH}_{2}-$ graphene nanocomposite: (1) self-assembly of $\mathrm{MgH}$ nanoparticles on graphene during solvothermal synthesis in a hydrogen atmosphere; (2) impregnation with $\mathrm{LiBH}_{4}$ solution; (3) solvent removal; and (4) heterogeneous nucleation of $\mathrm{LiBH}_{4}$ on $\mathrm{MgH}_{2}$ nanoparticles [61].

(a)

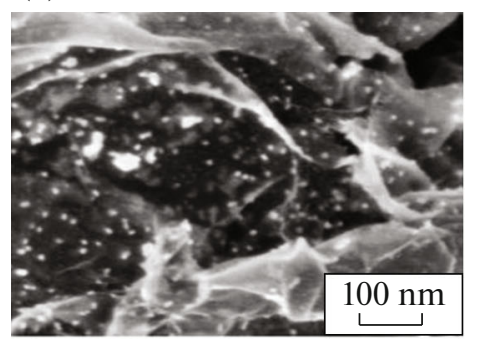

(b)

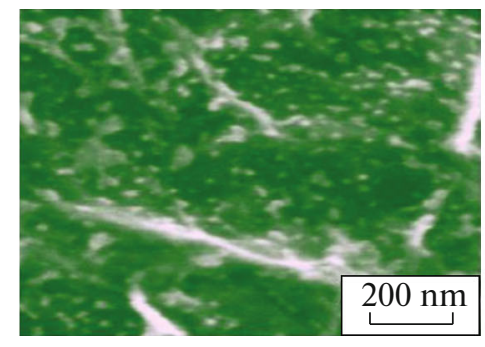

(c)

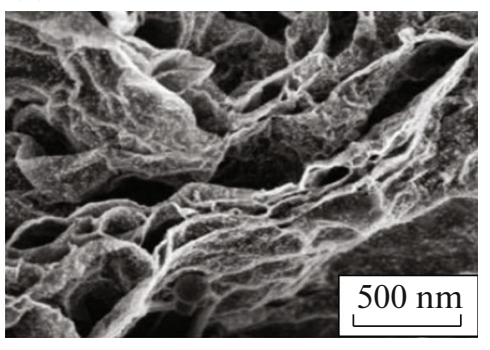

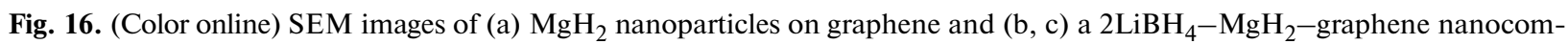
posite [61].

\section{GRAPHENE-BASED MEMBRANES FOR THE PURIFICATION AND CONCENTRATION OF HYDROGEN}

For hydrogen power generation, resolution of the problems of concentrating hydrogen and purifying it from impurities is of paramount importance. There are various methods for industrial production of hydrogen, such as steam reforming of methane or natural gas, coal gasification, water electrolysis, and thermochemical methods [62]. Steam conversion of ethanol obtained in large quantities from renewable biomass to hydrogen is also used [63]. In all cases, additional purification of the target product is required. For example, hydrogen produced by steam reforming of methane, which is among the most widespread technologies today, inevitably contains methane impurities.

Membrane separation of gas mixtures, pressure swing adsorption, and cryogenic distillation are used for the concentration and purification of hydrogen. The last two methods are expensive and consume significant amounts of energy, although they allow pure hydrogen to be obtained. At present, membrane puri- fication methods are considered to be the most promising approach, since they provide an optimal costeffectiveness ratio [64]. The most important membrane characteristics, i.e., the permeability and selectivity, depend on the physical and chemical properties of the membrane materials. In industry, polymer membranes are mainly used [65-67]. Unfortunately, it is necessary to sacrifice permeability for the sake of selectivity or vice versa in this case. Research and development in other areas is actively continuing; much attention is paid to membranes with a nanostructured carbon selective layer, as well as with a mixed matrix membrane, including carbon nanomaterials [68-76]. Graphene is of particular interest. Indeed, it is a very promising membrane material with the smallest possible thickness (one atom), and it is strong, flexible, and chemically and thermally stable at the same time. Recently, various methods for its synthesis in rather large volumes have been developed. Of course, ideal graphene is impermeable for gases. It should be noted that it was recently experimentally shown that $\mathrm{H}_{2}$, unlike all other gases, penetrates a graphene monolayer in some degree [33] (Section 1). Nevertheless, this fact can be explained by the pres- 

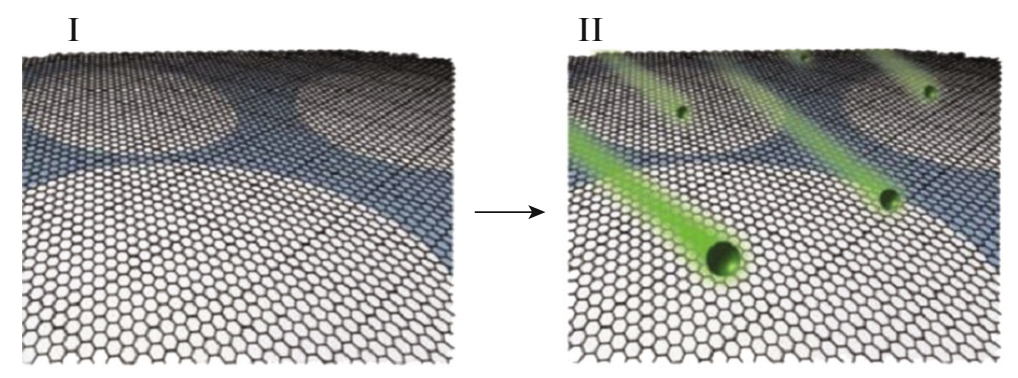

III
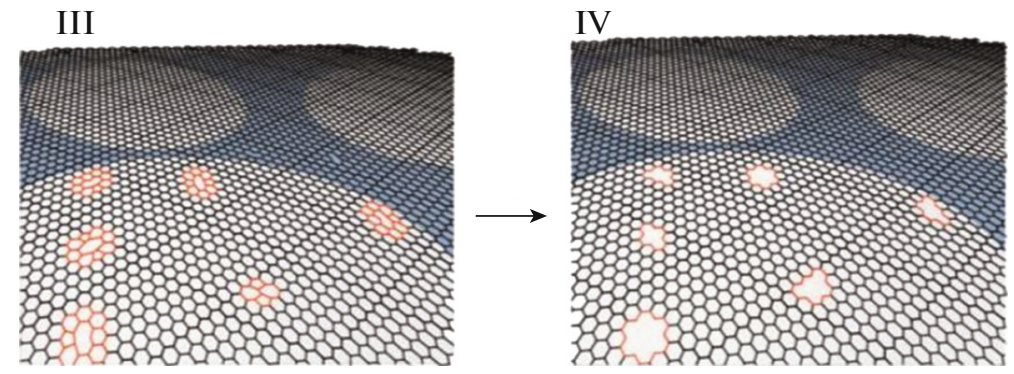

Fig. 17. (Color online) Schematic representation of the process of creating controlled subnanometer pores in graphene: (I) graphene on a grid for TEM, (II) bombardment with gallium ions, (III) bombardment creates defects, and (IV) chemical etching turns defects into pores [80].

ence of crimples and waves on the surface (surface curvature effects), i.e., the reason for that is the imperfection of graphene.

The main lines in the development of graphenebased membranes are the creation of pores in the graphene plane and the design of channels in graphene layers (with use of GO) [65-67, 77-79].

According to both theoretical estimates and some experimental data, nanoporous graphene can offer high permeability and selectivity in the separation of hydrogen-containing gas mixtures. The difficulty lies in creating the required number of pores with the desired size. Ion and electron beams and plasma treatment are traditionally used [80-84]. For example, pores with diameters ranging from $10 \mathrm{~nm}$ to $1 \mu \mathrm{m}$ were formed using a focused beam of $\mathrm{Ga}$ and $\mathrm{He}$ ions in bilayer graphene [81]. The authors of [80] showed that the bombardment of a graphene monolayer with gallium ions $\left(6 \times 10^{12} \mathrm{~cm}^{-2}\right)$ gives rise to defects, which transform into pores with a diameter of $0.4 \mathrm{~nm}$ and a pore density of about $10^{12} \mathrm{~cm}^{-2}$ after rather prolonged chemical etching with the use of an oxidizer (Fig. 17).

The authors of [83, 84] demonstrated that nanoporous graphene indeed provides record-breaking separation of the $\mathrm{H}_{2} / \mathrm{CH}_{4}$ mixture with high permeability. They developed a method for the formation of pores with a strictly controlled size (with an accuracy of tenths of a nanometer). Defects appear (mainly of the $s p^{3}$ type) when a graphene monolayer is treated with oxygen plasma $(1-2 \mathrm{~s})$, from which pores that allow to pass $\mathrm{H}_{2}$ and do not allow to pass $\mathrm{CH}_{4}$ and $\mathrm{C}_{3} \mathrm{H}_{8}$, i.e., with a size of no more than $0.38 \mathrm{~nm}$ (the sizes of the $\mathrm{H}_{2}, \mathrm{CH}_{4}$, and $\mathrm{C}_{3} \mathrm{H}_{8}$ molecules are 0.259 ,
0.38 , and $0.43 \mathrm{~nm}$, respectively), are developed as a result of subsequent etching in gaseous ozone for 2$10 \mathrm{~s}$ (Fig. 18). The density of these pores is $2.1 \times$ $10^{12} \mathrm{~cm}^{-2}$, which is sufficient to ensure high permeability. The proportion of larger pores is less than $0.002 \%$. The separation factor is $15-25$ for the $\mathrm{H}_{2} / \mathrm{CH}_{4}$ mixture and 38-58 for the $\mathrm{H}_{2} / \mathrm{C}_{3} \mathrm{H}_{8}$ mixture. If we consider the process of hydrogen evolution from a mixture that contains $35 \%$ hydrogen, then $90 \%$ of hydrogen with a purity of $90 \%$ will be recovered with a separation factor of 20 .

The authors of $[83,84]$ also developed a method for transferring, without damage, a graphene monolayer synthesized by chemical vapor deposition onto a microporous substrate, which is important for the practical applications of this membrane material.

Theoretical studies predict that membranes based on nanoporous graphene can show even higher efficiency than that found in the experiments, especially when the pores are modified with nitrogen. As shown in [85] with use of the density functional method, porous graphene and porous graphene that are modified with nitrogen to varying degrees (Fig. 19) provide the hydrogen permeability value required for industrial applications at 350,275 , and $125 \mathrm{~K}$ in configurations Figs. 19a, 19b, and 19c, respectively. The smaller the pores and the larger the gas molecules, the higher the energy barriers preventing the passage of gases through the pores. As a result, the gases studied in [85] can be arranged in the following sequence, in line with their permeability values, which are opposite to the sequence of the energy barrier values: $\mathrm{He}>\mathrm{H}_{2}>\mathrm{Ne}>$ $\mathrm{CO}>\mathrm{N}_{2}>\mathrm{Ar}>\mathrm{CH}_{4}$. A very high selectivity is 


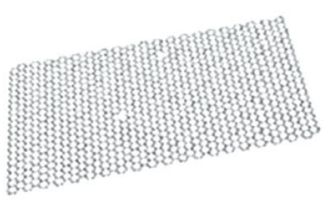

Graphene monolayer

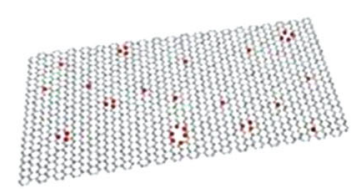

$\mathrm{O}_{2}$ plasma creates defects

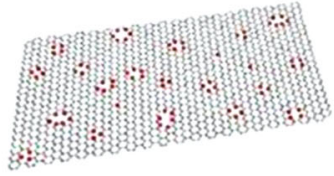

Development of pores during etching with $\mathrm{O}_{3}$

Fig. 18. (Color online) Schematic representation of pore formation in a graphene monolayer [84]. Nucleation of defects under the influence of $\mathrm{O}_{2}$ plasma. Development of pores during ozone etching.

required for hydrogen purification, and $\mathrm{H}_{2} / \mathrm{CH}_{4}>$ $\mathrm{H}_{2} / \mathrm{N}_{2}>\mathrm{H}_{2} / \mathrm{CO}$.

The authors of [77] compared the permeability and selectivity of graphene and polymer membranes in the separation of the $\mathrm{H}_{2} / \mathrm{CH}_{4}$ mixture. In simulation using the molecular dynamics method, graphene membrane configuration shown in Fig. 20 was used. Some of the carbon atoms were replaced by modifying hydrogen and nitrogen atoms. The distance between the pores $(4 \mathrm{~nm})$ and the pore density (around $6 \times 10^{12} \mathrm{~cm}^{-2}$ ) were close to the experimental data given above.

According to calculation results published in [77], the permeability of nanoporous graphene membranes is an order of magnitude higher than that of polymer membranes, while the selectivity is slightly lower, but of the same order of magnitude (it reaches 225 and can be 300-400 for some polymer membranes) (Fig. 21). A significant economic effect can be achieved from the standpoint of energy consumption for compaction and for the required area of the membrane, since the energy consumption for compaction does not depend on the selectivity when its value is higher than 200, and the gain in the area of the membrane will be substantial.

Owing to its unique thin-layered structure and the presence of functional groups, membranes based on graphene oxide (GO membranes) can also provide high permeability and selectivity and can be used in

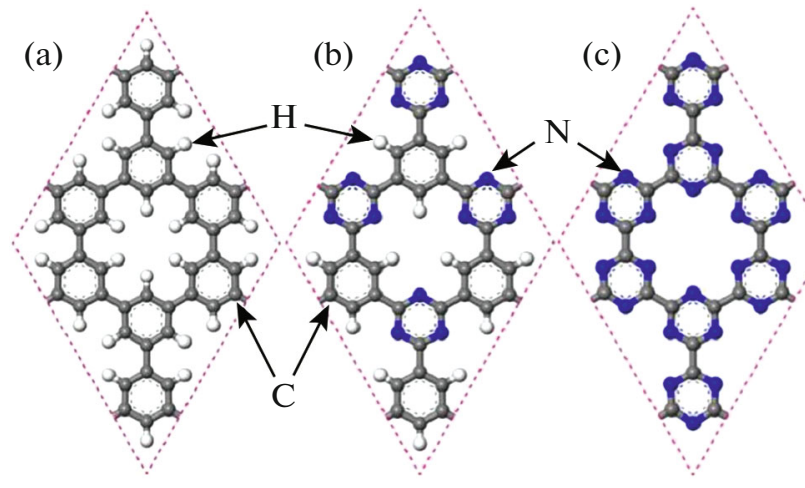

Fig. 19. (Color online) Structures used for calculations in [85]. practice for hydrogen purification or hydrogen evolution [66, 67, 73, 79, 86-93]. The homogeneous layered structures required to form membranes can be obtained from dispersions of GO flakes by dip coating, vacuum filtration, spray coating, layer-by-layer deposition, and other methods. It is important to optimize the flake sizes, the packing configuration, the overall thickness, and the interlayer distance. Without this, the diffusion path for gas molecules will be too winding and long, which will affect the permeability. At present, various types of GO membranes, in particular, free membranes (without a substrate); membranes deposited on porous polymers, ceramics, and other porous materials; and composite membranes, are being synthesized and investigated. Membranes without a substrate have the advantage of being thinner. Even with a total membrane thickness of several micrometers and small horizontal dimensions of the flakes, significant permeability and selectivity for the $\mathrm{H}_{2} / \mathrm{CO}_{2}$ mixture has been achieved [86]. Using molecular dynamics, the authors of [88] showed that the GO membrane effectively separates hydrogen and methane. In [93], the same method was used to study the $\mathrm{H}_{2} / \mathrm{CO}_{2}$ mixture and it was found that the selectivity depends on the interlayer distance and the distance between the pores located in different layers. Both experimental and theoretical data indicate that the question of the mechanism of transporting gas molecules is not completely clear. Apparently, the main mechanism for large molecules $\left(\mathrm{CH}_{4}, \mathrm{~N}_{2}\right.$, and $\left.\mathrm{CO}_{2}\right)$ is Knudsen diffusion, since the interlayer distance is rather large. This is confirmed by experimental datathe permeability of these gases is inversely proportional to the square root of the molecular weight [89, $90,92]$. However, the substantially higher permeability for hydrogen and helium indicates that another path contributes additionally. According to the authors of $[89,90]$, this is a straight narrow channel formed by defects (Fig. 22). Indeed, the layer structure and porosity depend on the method of synthesis of GO flakes and the membrane itself. Figure 23 shows SEM images of the surface and cross section of a GO membrane obtained by vacuum filtration on a macroporous polymer substrate [90].

Nanocomposite and hybrid membranes that consist of graphene or GO plates and a polymer or inor- 


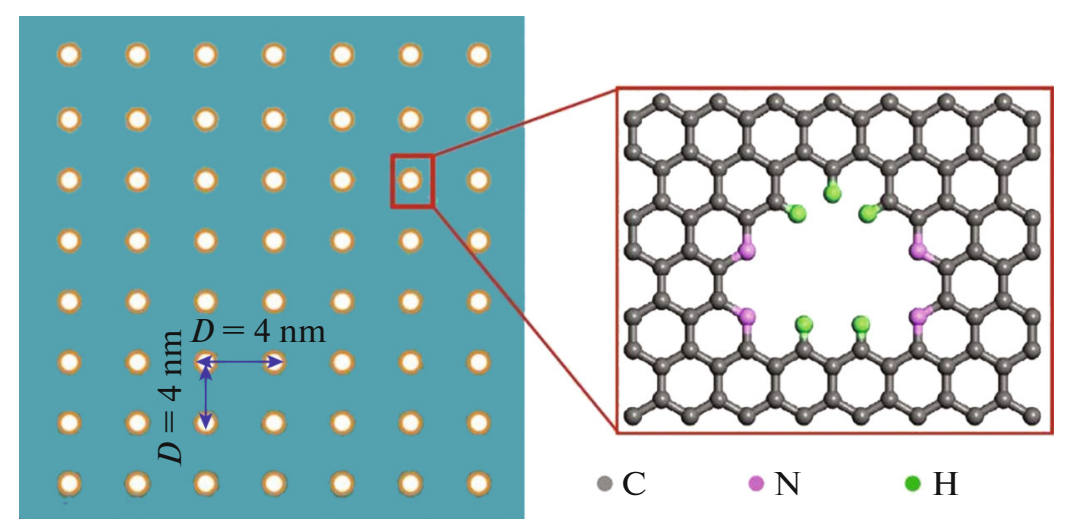

Fig. 20. (Color online) Configuration of a nanoporous graphene membrane and a nanopore structure [77].

ganic membrane material are also of interest for hydrogen purification [65, 66, 73]. As shown by the studies carried out at the Kurchatov Institute, microporous ceramic tubes made of aluminum oxide are a good substrate for the preparation of nanocomposite membranes with a nanocarbon selective layer [6870]. The authors of [94] synthesized a new type of such membranes with a GO monolayer deposited from a solution. The membranes showed stability, high hydrogen permeability, and good $\mathrm{H}_{2} / \mathrm{CO}_{2}$ selectivity (separation factor $>57$ ). The authors of [73] developed a method for the preparation of flexible 2D membranes with a mixed matrix, the main material of which is GO, while metal-organic framework (MOF) structures are used as nanosized microporous inclusions that increase permeability. To accomplish this, an ultrathin mixed membrane of $\mathrm{GO}$ and $\mathrm{CuO}$ nanoplates was created first by the method of successive precipitation from solutions, and then organic ligands were introduced into the solution and $\mathrm{CuO}$ was transformed into framework structures (Fig. 24). The synthesized membranes had high permeability; the $\mathrm{H}_{2} / \mathrm{CO}_{2}$ separation factor was 73.2.

Using the method of vacuum filtration, stable GO- $\mathrm{MoS}_{2}$ hybrid membranes were synthesized (Fig. 25) [95]. A $60 \mathrm{~nm}$ thick membrane containing about $75 \mathrm{wt} \% \mathrm{MoS}_{2}$ provided high hydrogen permeability and an $\mathrm{H}_{2} / \mathrm{CO}_{2}$ selectivity of 26.7 , and a $150 \mathrm{~nm}$ thick membrane containing about 29 wt $\% \mathrm{MoS}_{2}$ was more selective (44.2), but its permeability was lower by a factor of about 2.6. In general, the $\mathrm{GO}-\mathrm{MoS}_{2}$ hybrid membrane has better permeability and selectivity in comparison with the individual $\mathrm{GO}$ and $\mathrm{MoS}_{2}$ membranes; there is a synergistic effect between them. In the hybrid membrane, the layer packing was the same as in the pure GO membrane, but the addition of $\mathrm{MoS}_{2}$ nanoplates led to the formation of pores (the higher the concentration of $\mathrm{MoS}_{2}$, the higher the pore density). From the standpoint of practical application, it is important that the hybrid membrane has higher stability.
As mentioned above, the industry is currently mainly using polymer membranes, with either permeability or selectivity having to be sacrificed. Researchers are trying to overcome these problems by adding graphene materials to the polymer. Various versions of mixed matrix membranes are being developed. According to the authors of [65], the best polymer is the Matrimid polyimide. It is a thermostable material with sufficient mechanical strength and good gas transportation properties, especially for hydrogen purification and concentration. Three types of films that can serve as membrane materials were synthesized from a solution of a powder of this polymer mixed with suspensions of GO nanoplates. We used the GO samples obtained from graphite oxide by ultrasonic exfoliation, thermal reduction (T-RGO), and chemical reduction (C-RGO). According to the $\mathrm{X}$-ray diffraction data, the thicknesses of GO nanoplates were $5.62,0.92$, and $0.97 \mathrm{~nm}$ for GO, T-RGO, and C-RGO, respectively; at the same time, the numbers of layers were 6,3 , and 2 , and the interlayer distances were $0.89,0.31$, and $0.41 \mathrm{~nm}$, respectively. The SEM images of cross sections of three membranes

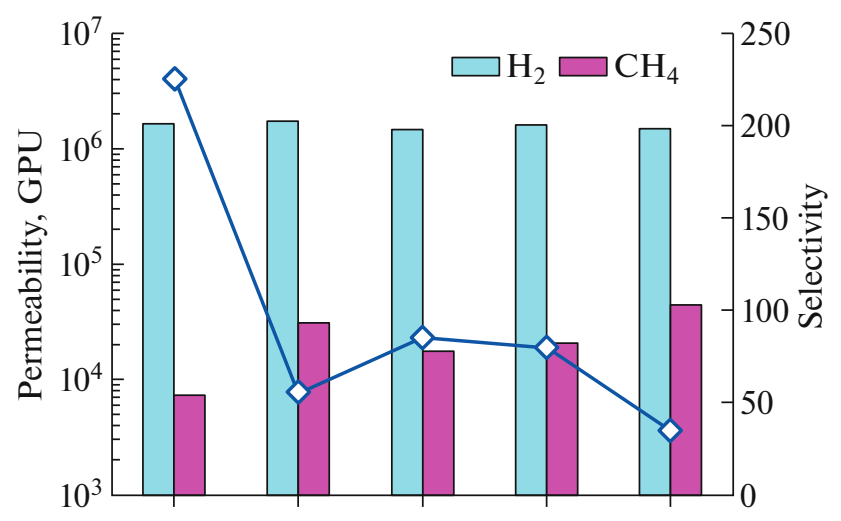

Fig. 21. (Color online) Permeability (histogram) and selectivity (line) for different hydrogen-methane ratios in the mixture $(5: 1,5: 2,5: 3,5: 4$, and $5: 5)[77]$. 


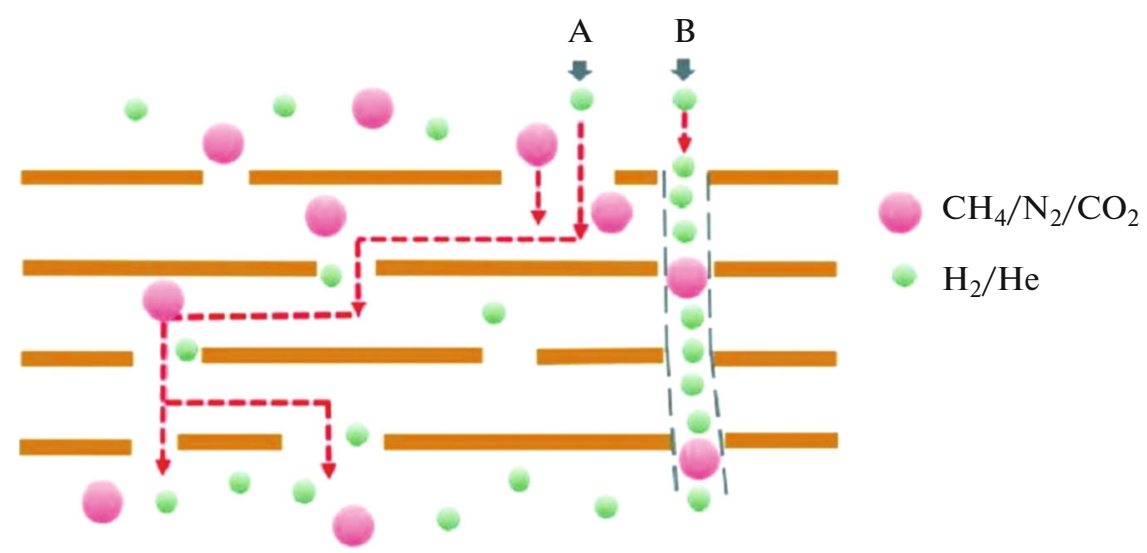

Fig. 22. (Color online) Scheme of two possible transport routes in layered GO membranes [89, 91].
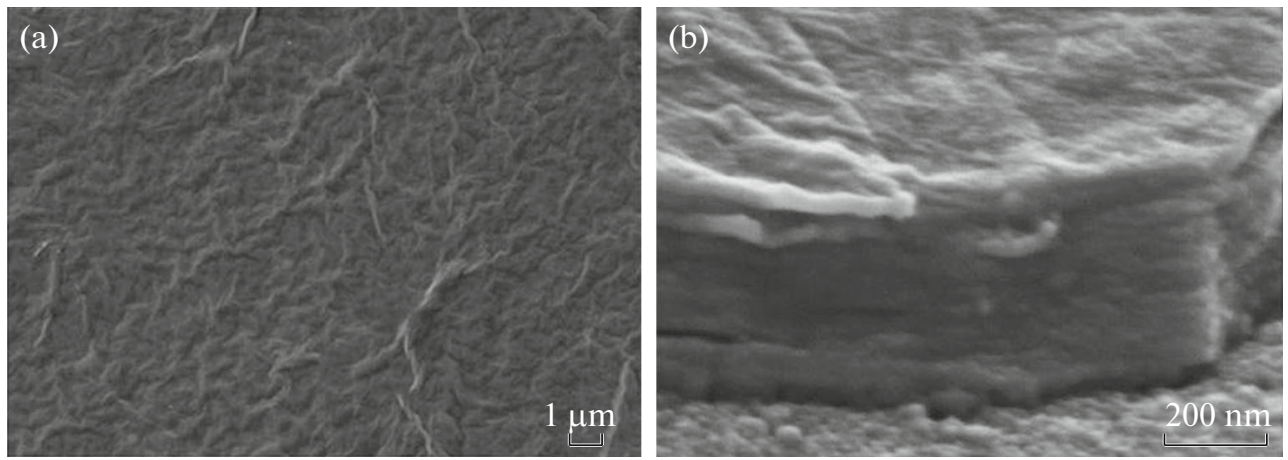

Fig. 23. SEM images of the surface and cross section of the GO membrane obtained by vacuum filtration on a macroporous polymer substrate [90].

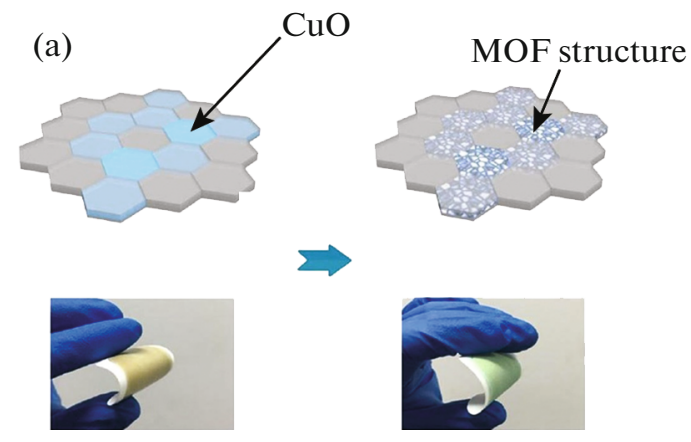

(b)

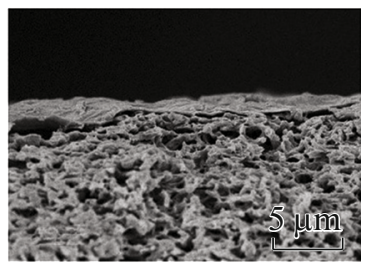

Fig. 24. (Color online) (a) Scheme of the synthesis of a flexible GO membrane. CuO nanoplates are embedded in the GO matrix. MOF structures are formed in situ as a result of the reaction of $\mathrm{CuO}$ with organic ligands in a solution. (b) SEM image of the membrane cross section [73].

containing 0.4 wt $\% \mathrm{GO}$ and the SEM image of the initial polymer are shown in Fig. 26. As can be seen, graphene nanoparticles are uniformly distributed and each of them is surrounded by a polymer cell.

Gas transport in polymer membranes follows the dissolution-diffusion mechanism. In composite membranes, graphene inclusions have an effect on the diffusion. When gas molecules encounter an obstacle in the form of graphene nanoplates, they can either return to the polymer matrix or penetrate between the layers. The particular mechanism, whether it is Knudsen diffusion or a molecular sieve effect, depends on the gap between the layers. Thus, molecules of all studied gases $\left(\mathrm{H}_{2}, \mathrm{CO}_{2}, \mathrm{O}_{2}, \mathrm{~N}_{2}\right.$, and $\left.\mathrm{CH}_{4}\right)$ in the case of a GO membrane can pass not only through the polymer, but also through the graphene phase with an 


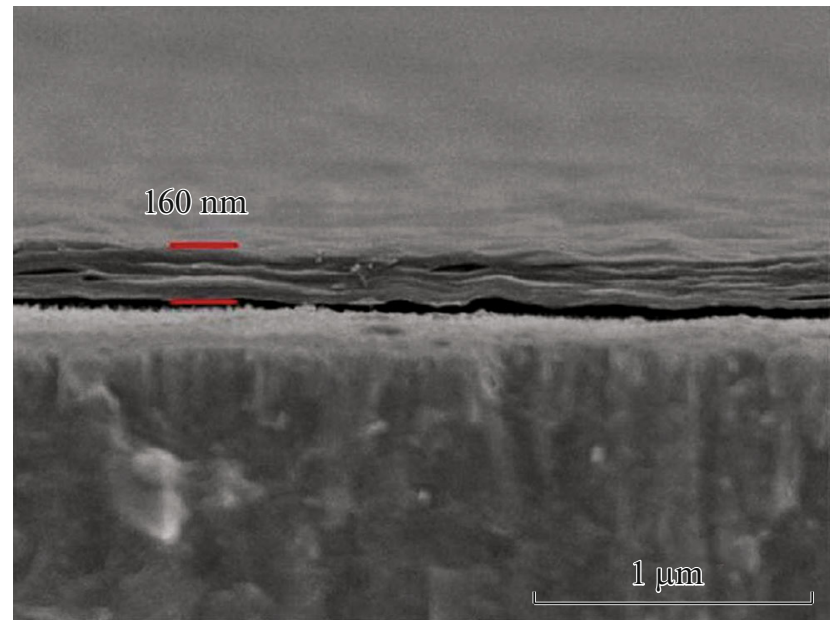

Fig. 25. (Color online) Graphene oxide- $\mathrm{MoS}_{2}$ hybrid membrane with a thickness of $160 \mathrm{~nm}$ [95].

interlayer distance of $0.89 \mathrm{~nm}$ (Fig. 27). The gas transport properties are only slightly improved compared to the polymer membrane. In contrast to this, membranes with T-RGO and C-RGO with interlayer distances of 0.39 and $0.41 \mathrm{~nm}$ exhibit extremely high selectivity in the processes involving hydrogen. The $\mathrm{H}_{2} / \mathrm{CH}_{4}$ selectivity at a concentration of $0.2 \mathrm{wt} \% \mathrm{GO}$ reaches 226 for a membrane with T-RGO and 231 for a membrane with C-RGO (it is 50 for a polymer membrane). The $\mathrm{H}_{2} / \mathrm{N}_{2}$ selectivity for these membranes increases by a factor of about 2 relative to the initial polymer membrane. Thus, the new membranes are promising for hydrogen purification in the processes of its production from natural gas, as well as for the extraction of hydrogen from the purge gases of ammonia synthesis.

The development of chemically and thermally resistant graphene-based membrane materials that provide high permeability and selectivity can lead to significant progress in membrane technologies, which is crucial for solving the problems of hydrogen power generation. The unique material as graphene has many other applications, including fighting infections. Scientists in many countries believe that it will play an important role in defeating the coronavirus infection COVID-19 and will be used both for diagnosis (sensors) and protection (filters, masks (Fig. 28)) [96]. Chinese researchers have already proposed a method for functionalizing conventional surgical masks by applying graphene coatings. The new masks are superhydrophobic; they can be sterilized simply in the sun and used repeatedly [97].

\section{APPLICATION OF GRAPHENE IN ELECTROCATALYTIC LAYERS \\ OF POLYMER ELECTROLYTE MEMBRANE FUEL CELLS}

Power plants based on Polymer Electrolyte Membrane (PEM) FCs are among the most promising ones because of their low operating temperature, low noise
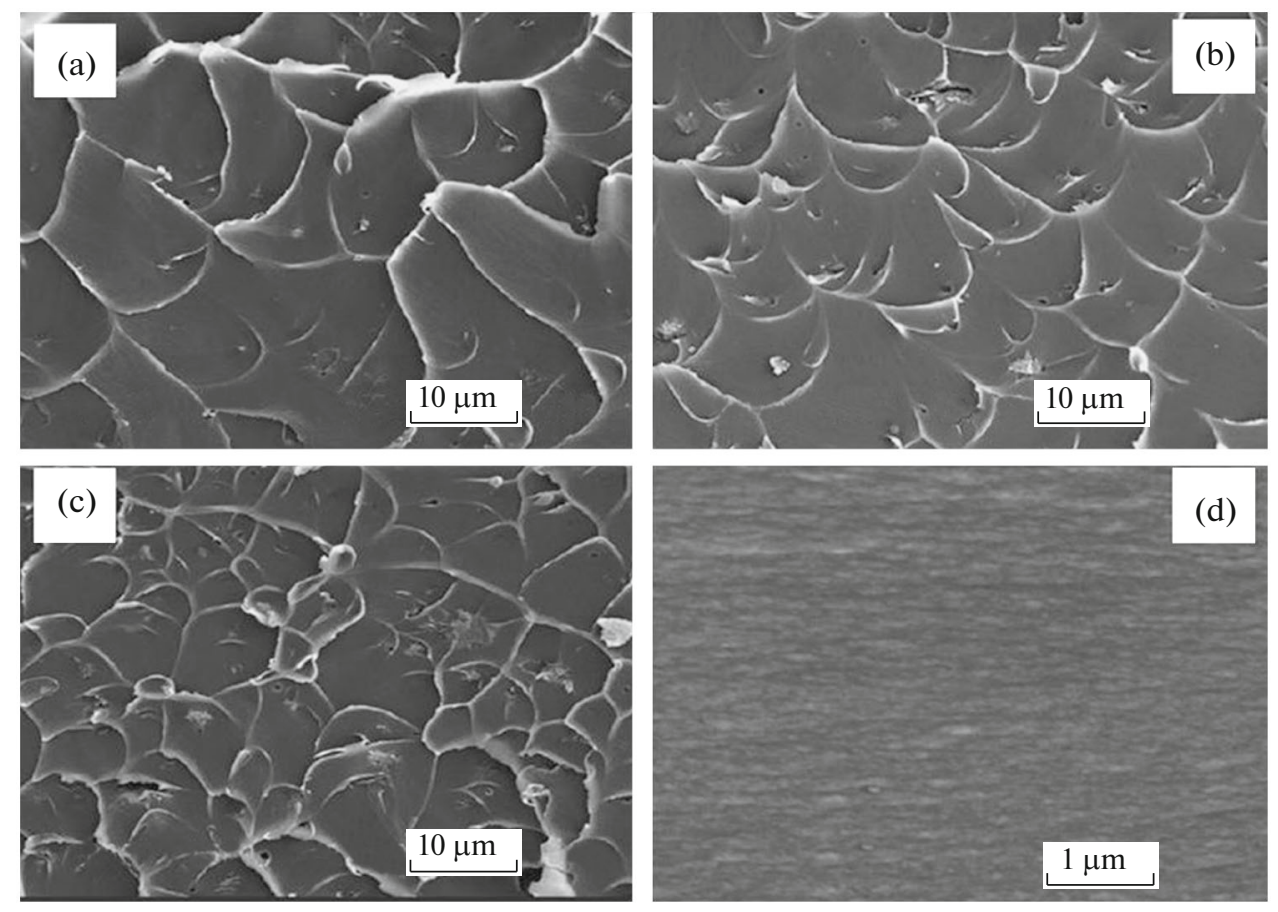

Fig. 26. SEM images of cross sections of three composite membranes containing 0.4 wt $\%$ of (a) graphene oxide GO, (b) T-RGO, (c) C-RGO, and (d) SEM image of the initial polymer [65]. 


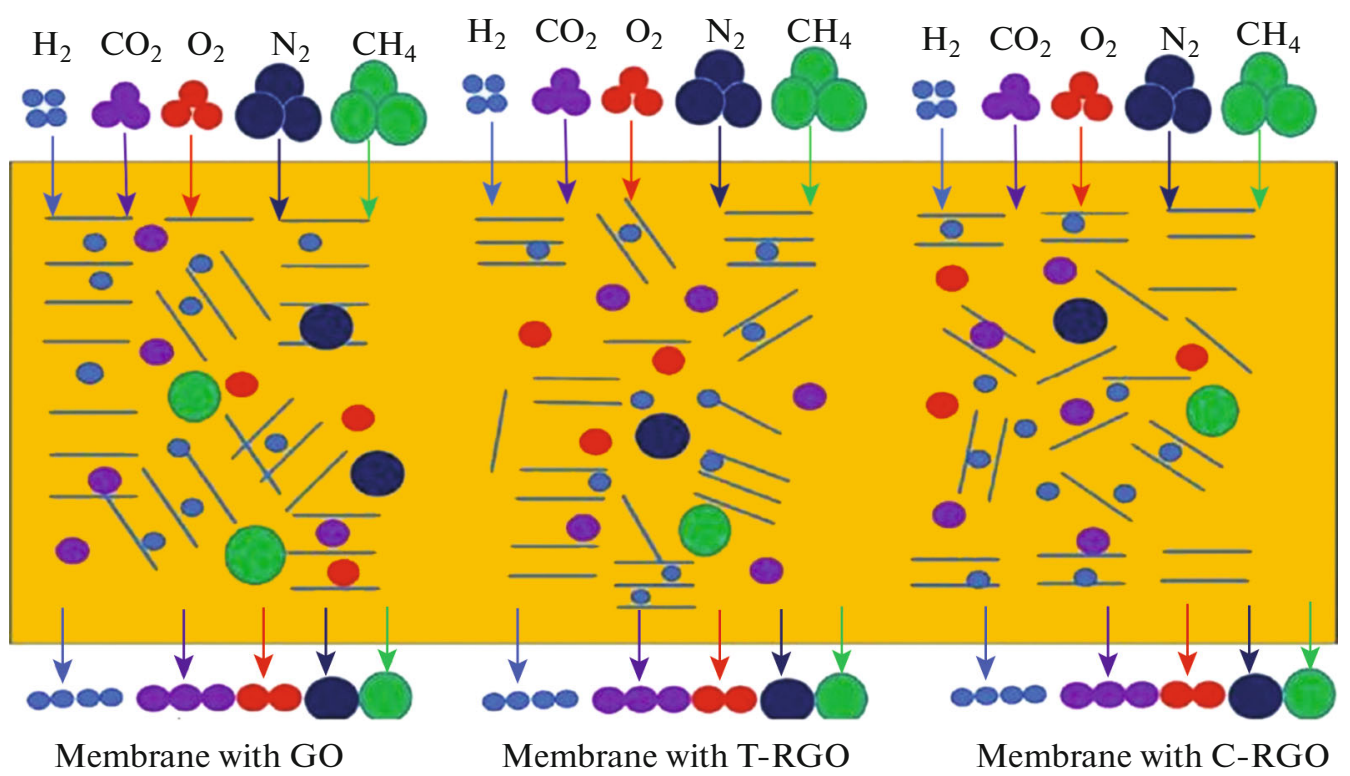

Fig. 27. (Color online) Different diffusion paths for gas molecules in three types of membranes [65].

level, ability to quickly start, high specific power, and environmental friendliness. PEMFCs have been developed for use in small power generators (with a power capacity in the range from $1 \mathrm{~kW}$ to $5 \mathrm{MW}$ ) installed directly in consumption areas, such as hospitals, hotels, and office buildings, owing to their compact design. They can also be used in portable electronic devices $(20-100 \mathrm{~mW})$, such as laptops, mobile phones, and camcorders, because they are lighter and smaller then batteries, have longer run times, faster response, and do not require recharging from power grid (unlike rechargeable batteries). Transport, for example, buses, cars, motorcycles, and unmanned aerial vehicles, is another important niche for the use of PEMFCs (with a power of 5-500 kW). The development of this area is facilitated by the constant growth of the prices of fossil fuels, which is caused by their limited availability and the tightening of environmental legislation in many countries of the world in order to reduce the intensity of greenhouse gas emis-

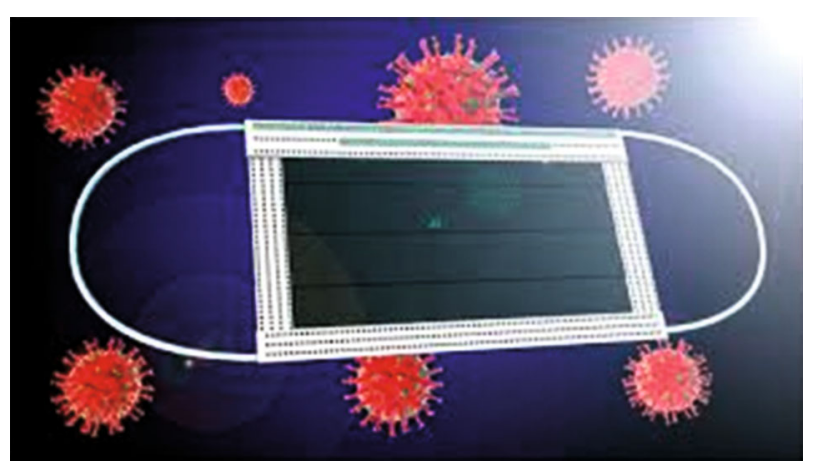

Fig. 28. (Color online) Mask [97]. sions [98]. In addition, PEMFCs, which are currently being actively implemented in the world power production, play an important role in power plants and power systems based on renewable energy sources because of their properties, such as low inertia, high explosion and fire safety, and short response times to power load changes.

The limitation of the lifetimes of PEMFCs, which is mainly associated with the degradation of electrodes and membranes and with the influence of impurities contained in the supplied gases, is the most important restrictive factor. Poisoning of the electrocatalyst surface (for example, with $\mathrm{CO}$ molecules) leads to the deterioration of FC performance due to a decrease in the number of active sites [99]. The electrocatalytic layers, in which electrochemical half-reactions that comprise a total current-forming reaction occur, are among the main components of PEMFCs. The use of electrocatalysts, which usually, Pt nanoparticles on a carbon support [100], ensures high rates of half-reactions.

At present, various types of carbon blacks (such as Vulcan XC-72, Ketjen Black, etc.) are most widely used as supports for electrocatalysts. The properties of these carbon supports, including their relatively high specific surface area (up to $250 \mathrm{~m}^{2} / \mathrm{g}$ for XC-72 [101]), porous structure, electrical conductivity, mechanical strength, and corrosion resistance, largely determine the efficiency of the catalysts and, consequently, the performance of the electrochemical system. The most important drawbacks of carbon black include the presence of organosulfur impurities, deep micropores on the surface of the material (the proportion of micropores is up to $47 \%$ [100]), and still insufficient stability. Catalyst nanoparticles are trapped in micropores and 
have no access to reagents and electrolyte, as a result of which the catalytic activity decreases [101, 102]. Carbon black is also unstable under strongly acidic/alkaline conditions in FCs, which is manifested in the form of corrosion of the carbon support and detachment of catalyst nanoparticles [101], which leads, in turn, to substantial deterioration in the performance of PEMFCs.

On the whole, the key differences of graphene and its derivatives from carbon black traditionally used as a support for electrocatalytically active Pt nanoparticles (for example, Vulcan XC-72 [103]) are their high specific surface area, chemical stability, and graphite-like structure [104] that provides higher electrochemical corrosion resistance of the support, as well as strong metal-support interaction, which protects catalytically active Pt nanoparticles from aggregation and dissolution [105, 106]. Likewise, the advantages of graphene-like materials can be attributed to their layered structure, which can facilitate the mass transfer of reagents [107] and can increase the tolerance of the anode catalyst of a PEMFC based on Pt to $\mathrm{CO}$ poisoning [107]. On the other hand, graphene-like materials have a number of drawbacks that delay their use as supports. These drawbacks include strong agglomeration of Pt nanoparticles during the synthesis of catalysts, restacking of graphene nanosheets due to van der Waals interaction, and the tendency of graphene nanosheets to agglomerate in aqueous solutions [108]. The properties of catalysts based on graphene-like materials depend on various factors, such as the methods used for their synthesis and drying; the techniques used for catalytic ink preparation; the mechanical, chemical, and physical treatment of the catalyst; etc. [109-112].

In [109], a Pt/RGO catalyst prepared by the simultaneous reduction of graphene oxide and $\mathrm{H}_{2} \mathrm{PtCl}_{6}$ using $\mathrm{NaBH}_{4}$ as a reducing agent was investigated. The Pt content in the catalyst was $45 \mathrm{wt} \%$, and the specific electrochemically active surface area (EASA) was $44.6 \mathrm{~m}^{2} / \mathrm{g} \mathrm{Pt}$. A study of the electrochemical activity of the catalyst in the oxidation of methanol by cyclic voltammetry showed that the resulting Pt/RGO electrocatalyst is substantially more active than the Pt/Vulcan catalyst prepared in a similar way. The maximum current density of the Pt/RGO catalyst was about $200 \mathrm{~mA} / \mathrm{mg} \mathrm{Pt}$ at $0.652 \mathrm{~V}$ (relative to the silver chloride reference electrode), which is almost twice as high as that of the Pt/Vulcan catalyst. In [111], the authors showed the effect of the drying procedure for a $\mathrm{Pt} / \mathrm{RGO}$ catalyst synthesized by the same method as in $[109,110]$ on the properties of the catalytic ink. In the case of traditional drying, the catalyst is highly aggregated, so redispersion of the ink for their application is practically impossible even with use of powerful ultrasonic treatment. Much attention is paid to dispersing graphene sheets in water or other solvents by adding surfactants or functionalizing the graphene surface. However, surfactants have a negative effect on the course of reactions in FCs and can also lead to deteriorating the electronic conductivity [112]. To stabilize graphene and prevent irreversible aggregation and folding of planes during drying and heat treatment, it was proposed to apply lyophilization in [111], which made it possible to prevent strong aggregation in the Pt/RGO system. The maximum current density of the Pt/RGO electrocatalyst in the methanol oxidation reaction was $182.6 \mathrm{~A} / \mathrm{g}$, while it was only $77.9 \mathrm{~A} / \mathrm{g}$ for the Pt/Vulcan XC-72 catalytic system. Annealing the $\mathrm{Pt} / \mathrm{RGO}(\mathrm{Pt} / \mathrm{RGO}-\mathrm{O})$ catalyst at $300^{\circ} \mathrm{C}$ for $2 \mathrm{~h}$ in an $\mathrm{N}_{2}$ atmosphere made it possible to increase the maximum current density to $261.6 \mathrm{~A} / \mathrm{g}$ due to factors, such as the enhancement of the interaction between $\mathrm{Pt}$ and the support (RGO), the appearance of additional active Pt sites, and the partial destruction of surface functional groups, which led to a decrease in the number of defects on the RGO surface and an increase in its stability, as well as an increase in the crystallinity of Pt nanoparticles.

In [110], the Pt/RGO electrocatalyst was synthesized by the polyol method, but in two different ways. In one case, the reduction of graphene oxide and $\mathrm{H}_{2} \mathrm{PtCl}_{6}$ was carried out in ethylene glycol at once, while GO in the second case was preliminarily reduced with $\mathrm{NaBH}_{4}$ and then was placed in ethylene glycol to deposit Pt nanoparticles on its surface. Voltametric measurements, as well as the results of testing electrocatalysts in PEMFCs, showed that the catalyst obtained in a two-stage process was more active in the methanol oxidation reaction.

In [113], the authors succeeded in synthesizing bimetallic Pt-Ru nanoparticles on fibers of the carbon cloth wrapped in RGO nanosheets (Fig. 29). The need for such a modification of carbon cloth is explained by the fact that nanoparticles weakly interact with the surface of the fibers despite the high surface area of the cloth, and their degree of dispersion remains low [114]. The modification promotes the formation of uniformly distributed small size electrocatalyst nanoparticles with a large surface area. In [115], a multilayer electrocatalyst was synthesized in the form of carbon nanofibers (CNFs) wrapped in RGO sheets, on the surface of which $\mathrm{Pt}$ nanoparticles were deposited. These particles play the role of a spacer for the next RGO layer, onto which Pt nanoparticles are again reduced. Cyclic voltammetry studies of the catalyst in a solution of $1 \mathrm{M} \mathrm{KOH}$ and $1 \mathrm{M} \mathrm{CH}_{3} \mathrm{OH}$ showed that a multilayer electrode has a higher catalytic activity in the oxidation of methanol in comparison with the $\mathrm{Pt} / \mathrm{RGO} / \mathrm{CNF}$ and $\mathrm{Pt} / \mathrm{CNF}$ catalytic systems.

Graphene also attracts great attention as a support of electrocatalysts for hydrogen-oxygen (-air) FCs [116-119]. 


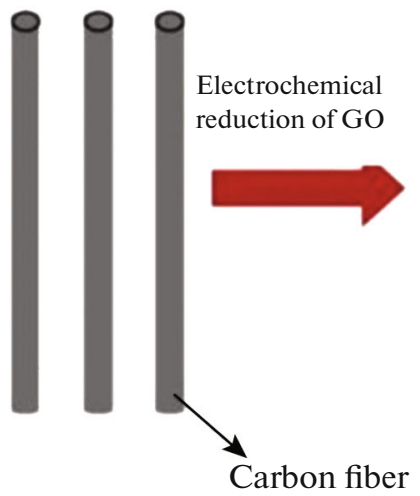

Carbon fabric

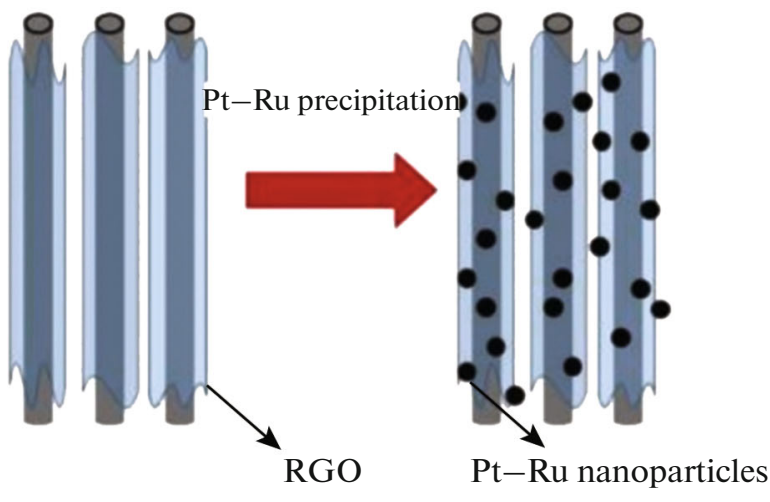

$\mathrm{RGO} / \mathrm{CF} \quad \mathrm{Pt}-\mathrm{Ru}$ nanoparticles/RGO/CF

Fig. 29. (Color online) Scheme of the synthesis of $\mathrm{Pt}-\mathrm{Ru}$ nanoparticles on carbon fabric fibers wrapped in RGO (CF, carbon fabric; GO, graphite oxide) [113].

In [116], it was possible to synthesize a number of platinum catalysts on RGO as a support with an EASA value of more than $70 \mathrm{~m}^{2} / \mathrm{g} \mathrm{Pt}$. In particular, we studied $\mathrm{Pt} / \mathrm{RGO}$ catalysts modified with polydiallyldimethylammonium (PDDA), which is used to functionalize the graphene surface in order to improve the dispersion of Pt nanoparticles on the RGO surface. Thus, the EASA value of the electrocatalytic layer based on PDDA-modified RGO was found to be $78.6 \mathrm{~m}^{2} / \mathrm{g} \mathrm{Pt}$ versus $72.5 \mathrm{~m}^{2} / \mathrm{g}$ Pt for the catalyst based on unmodified RGO. In the course of the study, it was possible to achieve a maximum power density above $700 \mathrm{~mW} / \mathrm{cm}^{2}$ in the composition of an air-hydrogen fuel cell. The EASA value after accelerated stress testing (AST) was $23.5 \%$ of the initial value for the Pt/RGO catalytic system and $43 \%$ of the initial value for the Pt/RGO-PDDA system.

As was shown in [120], the use of ethylene glycol as a reducing agent makes it possible to obtain electrocatalysts based on $\mathrm{Pt}$ and RGO or graphene nanoplates (GNPs) with the highest EASA and activity in the oxygen reduction reaction (ORR) with uniform distribution of nanoparticles over the support surface. In addition, it was shown that $\mathrm{H}_{2} \mathrm{PtCl}_{6}$ turned out to be a more effective precursor of $\mathrm{Pt}$ nanoparticles than $\mathrm{K}_{2} \mathrm{PtCl}_{4}$. In [121], the authors gave two different and effective methods for the synthesis of Pt nanoparticles on GNP as a support. The first method was supercritical $\mathrm{CO}_{2}$ deposition and the second method was microwave irradiation. The advantage of the former is a decrease in the degree of agglomeration of Pt nanoparticles during reduction due to the strong interaction between the adsorbed precursor ions and the surface of GNPs, which makes it possible to obtain Pt nanoparticles with an average size of less than $1.5 \mathrm{~nm}$ and to increase the corrosion resistance of the catalyst as a whole (against corrosion of the support). The authors also proposed a flexible one-step method for depositing Pt nanoparticles onto the RGO surface by plasma jet treatment of a solution of $\mathrm{H}_{2} \mathrm{PtCl}_{6}$. The resulting electrocatalyst demonstrated high activity in the ORR in both acidic and alkaline solutions [122].

The results [123, 124] showed that RGO and graphite oxide can also be used as an electrocatalyst support for high-temperature PEMFCs based on a polybenzimidazole membrane.

The $\mathrm{pH}$ of the medium, the $\mathrm{Pt}$ precursor, the $\mathrm{OH}^{-} / \mathrm{Pt}$ ratio, and the properties of the initial graphite oxide are also of great importance in the synthesis of electrocatalysts based on RGO by the polyol method. The best result from the standpoint of morphology (particle size, uniformity of their distribution over the support surface, etc.) was achieved using $\mathrm{H}_{2} \mathrm{PtCl}_{6}$, freeze-dried GO prepared by the Hammers method with a graphite : oxidizer ratio of $1: 6$ and a $\mathrm{pH}$ value of 12 [125].

An original method of using graphene as a support of molecular electrocatalysts for hydrogen evolution was demonstrated in the studies of Russian researchers, including those performed at the National Research Center Kurchatov Institute [126]. The clathrochelate complexes of $\mathrm{Fe}, \mathrm{Co}$, and $\mathrm{Ru}$ can be adsorbed on the developed RGO surface, which makes it possible to significantly increase the efficiency and productivity of the cathode of a PEM water electrolyzer [127, 128]. A similar approach can be used in the case of molecular electrocatalysts of the ORR, etc. [129].

The combination of graphene and carbon black, which is traditionally used as a support for electrocatalysts, has been recognized as a successful approach $[130,131]$. The authors of [132] developed an electrocatalyst on a mixed support based on graphene and carbon black, in which the optimum carbon black content was $25 \%$. This electrocatalyst demonstrated substantial improvement in the characteristics of a FC operating at a high current density. The maximum specific power of the FC was $2.58 \mathrm{~kW} / \mathrm{g}$ Pt or $645 \mathrm{~mW} / \mathrm{cm}^{2}$. 
(a)

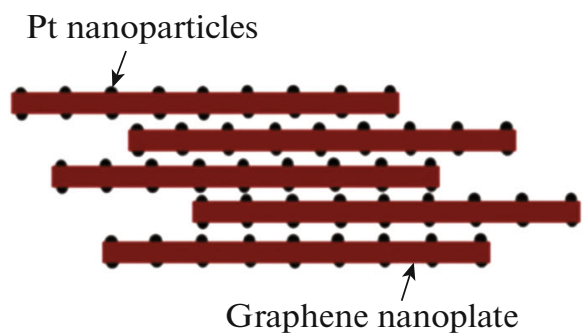

(b)

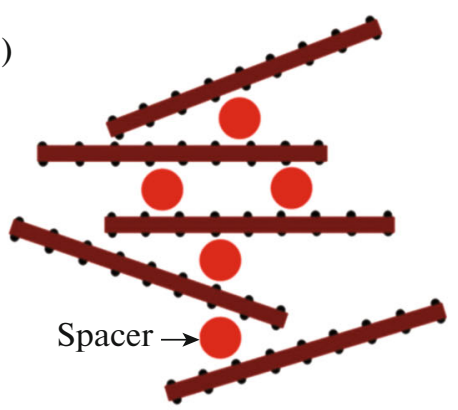

Fig. 30. (Color online) Schematic diagram of an electrocatalytic layer formed on an electrocatalyst with RGO as a support (a) without using a spacer and (b) using carbon black as a spacer between RGO flakes [117].

In addition, it was shown that intercalation of carbon black between RGO sheets prevents strong folding and agglomeration of RGO nanosheets [133]. In [117], the authors also suggested that spherical carbon black particles would act as spacers between graphene sheets (Fig. 30). It was shown that the presence of carbon black particles promotes exfoliation of graphene decorated with $\mathrm{Pt}$ nanoparticles and also contributes to an increase in the distance between RGO sheets and an increase in the permeability of the catalytic layer for reagents. The optimum carbon black content was $25 \%$. The EASA area increased by about $50 \%$ because of carbon black addition, although its value cannot be considered sufficiently high $\left(48 \mathrm{~m}^{2} / \mathrm{g}\right.$ Pt for a composite support). It was shown in [134] that the use of carbon black as a spacer between B-doped RGO nanoflakes leads to a decrease in both the ohmic and polarization resistance of the membrane-electrode unit. Similarly, the addition of multiwalled CNTs to an electrocatalytic layer based on a Pt/graphene electrocatalyst promotes better transport of reactants and reaction products (due to a change in the pore structure), provides better electrical contact between catalyst particles, and leads to an increase in the degree of Pt utilization [135].

As was shown in [136], Pt/RGO sheets and oppositely charged CNTs spontaneously form a sandwich structure; in solution, negatively charged CNTs are embedded between the sheets of a pre-synthesized positively charged Pt/RGO composite. Being sandwiched between Pt/RGO sheets, carbon nanotubes promote mass transfer in the $\mathrm{FC}$ electrocatalytic layer and prevent restacking of the Pt/RGO layers. After AST, the electrochemically active surface area of the Pt/RGO-CNT(10) catalyst was $61 \%$ of the initial value, while the EASA areas of the $\mathrm{Pt} / \mathrm{RGO}$ and $\mathrm{Pt} / \mathrm{C}$ electrocatalysts dropped to about $20 \%$ of the initial value.

An original approach was demonstrated in [137139], which consisted in introducing oxygen-modified CNFs into the cathode along with a platinum catalyst on a support. The authors of [137] believe that the mechanism of the effect of oxygen-modified CNTs on the kinetics of electrochemical reduction of oxygen on platinum consists in the inclusion of the quininehydroquinone Red-Ox transition in the oxygen reduction process. Carbon nanotubes that are electrically bound to platinum reduce (because of the presence of hydroquinone groups) the oxygen adsorbed on it.

As mentioned above, electrocatalysts in which graphene or RGO nanoflakes are used as a support suffer from the tendency to agglomerate under the action of van der Waals forces [104]. In [135], the porous structure formed by multiwalled CNTs acted both as a medium for efficient transfer of reagents and reaction products, and as an electron-conducting grid.

The functional possibilities of using thermally expanded graphite in electrodes for chemical sources of electric current were shown in [140-142]. The efficiency of using thermally expanded graphite as a binder instead of polymer solutions and, at the same time, as a conductive component in the composition of electrodes for various chemical sources of electrical energy was demonstrated. Adding $1 \mathrm{wt} \%$ of RGO in a composite bipolar plate allows its conductivity to be increased (both longitudinal and transversal) and the maximum power density of a PEMFC to be increased by $10 \%$ [143].

Reduced GO can act as a functional additive to the electrocatalytic layer based on a traditional platinum catalyst, which makes it possible to increase the efficiency of FC operation in the region of high current densities [134, 144-146]. In this case, RGO nanosheets in the electrocatalytic layer act as spacers between the Vulcan XC-72 support particle agglomerates coated with $\mathrm{Pt}$ nanoparticles [147]. Owing to the high aspect number (ratio of length to thickness) of RGO nanosheets, the percolation limit with respect to the electronic conductivity of the active layer decreases in this case, which was confirmed by both simulation (Monte Carlo method) and experimental results. It was shown that the use of particles that form large agglomerates (CNFs) (up to $4 \mu \mathrm{m}$ ) in the electrocatalytic layer enables reducing the percolation limit with respect to the electronic conductivity of the layer, 

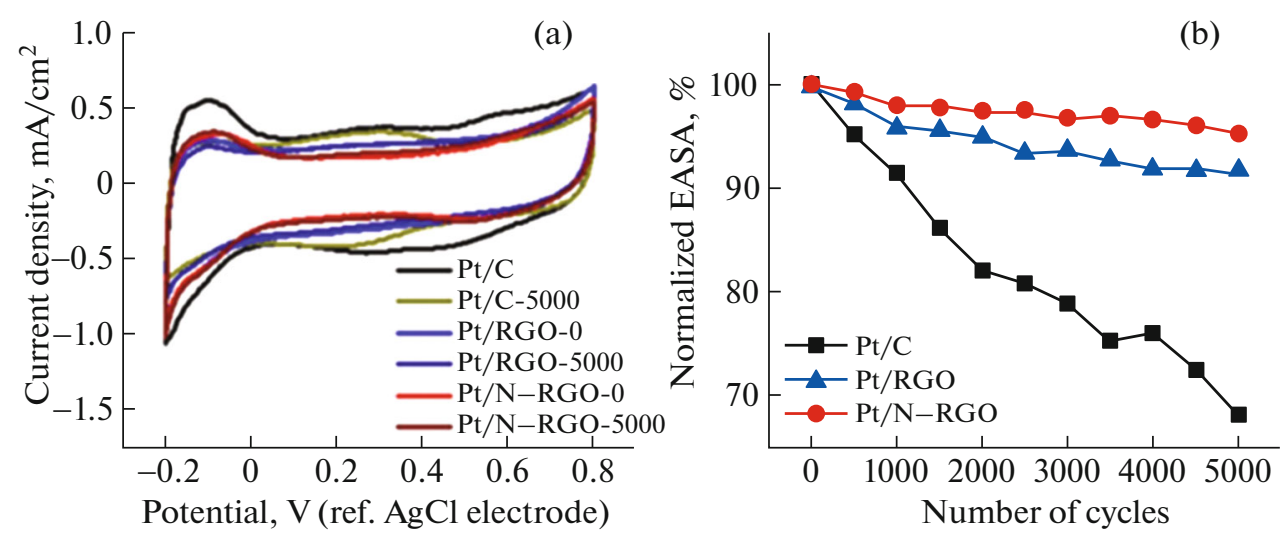

Fig. 31. (Color online) Results of accelerated stress testing of the Pt/N-RGO, Pt/RGO, and Pt/C electrocatalysts: (a) cyclic voltammograms of electrodes with $\mathrm{Pt} / \mathrm{N}-\mathrm{RGO}, \mathrm{Pt} / \mathrm{RGO}$, and $\mathrm{Pt} / \mathrm{C}$ before and after stress testing for 5000 cycles in a deaerated $0.1 \mathrm{M} \mathrm{HClO}_{4}$ solution; (b) comparison of the EASA values of electrocatalysts before and after stress testing [157].

increases the ionomer content, and facilitates the mass transfer of reagents and reaction products [147]. In view of the spatially developed structure and high electrical conductivity of RGO, a highly conductive grid (matrix) is formed in the structure of the catalytic layer, which was confirmed by the results of impedance measurements [144]. In addition, the porosity of the active layer and its permeability to reagents (hydrogen and oxygen) and the product of the electrochemical reaction (water) increase, which contributes not only to a slight decrease in the mass transport restrictions [134], but also to an increase in the utilization of Pt nanoparticles [136]. According to the results published in [148, 149], thermally expanded graphite can be used as a thermostabilizing functional additive, which makes it possible to increase the operating temperature of FC electrodes based on the Nafion proton-conducting polymer with the aim of increasing the operating current density, to reduce the platinum loading, and to increase the lifetime of the electrodes.

Reduced graphene oxide offers rich possibilities for modifying its surface properties. There are several approaches to imparting reversible redox properties to RGO. Surface modification by adsorption of organic molecules obviously possessing reversible redox properties, like quinine-hydroquinone cycles, is among the simple and obvious methods [150]. In some cases, it is possible to fix such organic molecules on the surface of graphene particles by means of strong chemical bonds. The functionalization of RGO by imparting reversible redox properties directly to the RGO particles themselves is another method, in which the ensembles of oxygen-containing functional groups acquire the ability to reversible redox reactions [151]. In addition, preparative methods make it possible to obtain RGO samples with different electrical conductivity, hydrophilicity, and donor-acceptor properties. Reduced graphene oxide doped with various elements $(\mathrm{N}, \mathrm{B}, \mathrm{P}, \mathrm{S}, \mathrm{O}$, and $\mathrm{F}$ ) seems to be a promising component of electrocatalysts [152, 153] for air-hydrogen fuel cells and electrolyzers, in particular, owing to a significant increase in the local density of Fermi energy states, which facilitates electron transfer from graphene carbon to chemisorbed oxygen, thereby facilitating the process of electrochemical reduction of oxygen [154].

Below we will discuss several examples of using modified graphene materials both as carriers of active Pt nanoparticles and as ORR electrocatalysts.

Frequently, GO (exfoliated graphite oxide) is an intermediate substance in the production of graphene, the surface of which contains a large number of oxygen-containing functional groups, including epoxy, carboxyl, and hydroxyl groups that can then be functionalized on each side of the sheet [155]. For example, nitrogenation (modification of the support with nitrogen) was simultaneously carried out during the reduction of graphite oxide to RGO [156]. Nitrogendoped GO turned out to be a more stable support than carbon black Vulcan XC-72 (after AST, the Pt/RGO-N electrocatalytic system lost $60 \%$ of EASA, while the Pt/Vulcan XC-72 catalyst lost 96\%). The Pt/RGO-N electrocatalyst, in which Pt nanoparticles were deposited on the surface of $\mathrm{N}$-doped RGO ( $\mathrm{N}$ atoms acted as bridges between Pt nanoparticles and the support), demonstrated a substantially higher specific activity in the ORR as compared to its commercial analogue because of the mutual synergistic effect of Pt nanoparticles and the heteroatom-doped RGO matrix, as well as owing to the small size $(2.8 \mathrm{~nm})$ and specific structure of Pt particles (111). Nitrogen atoms enable the transport of electrons, which leads to a decrease in the electrical resistance and prevents detachment, dissolution, migration, and aggregation of nanoparticles on the RGO surface during accelerated stress-testing (Fig. 31) [157].

In [158], a highly stable Pt/FeNGnPs electrocatalyst was developed, in which Pt nanoparticles are fixed on the surface of graphene-like nanoplates doped with 
(a)

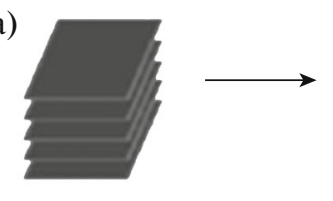

Graphite

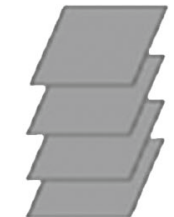

Graphite oxide

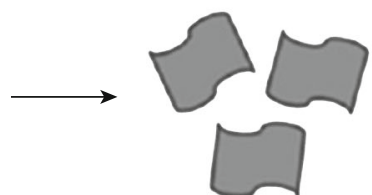

Graphene oxide

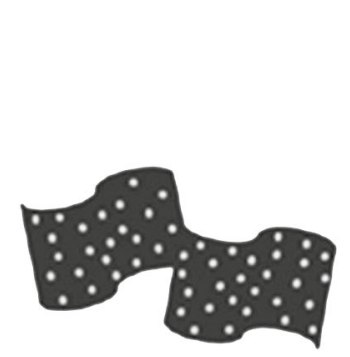

$\mathrm{Pt}-\mathrm{BG}$
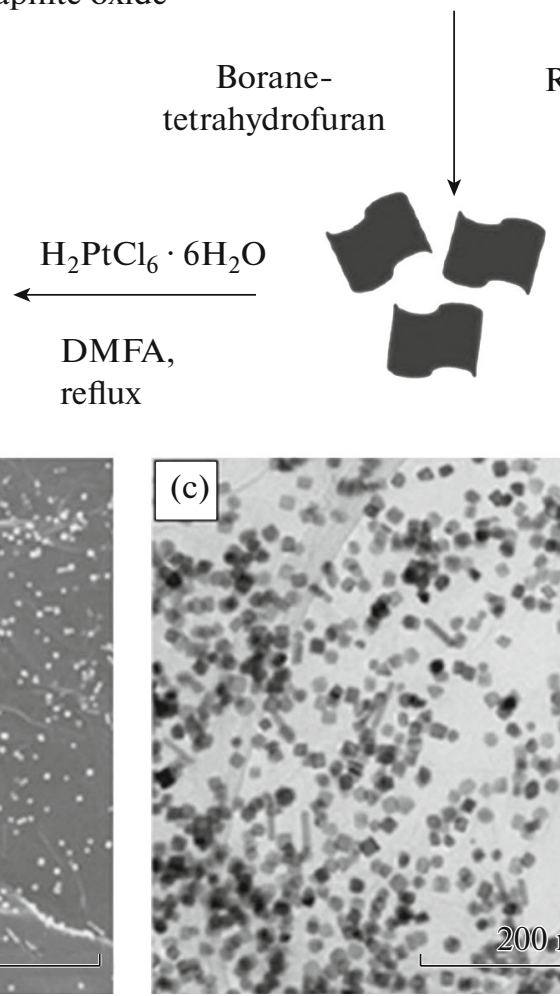

Reflux
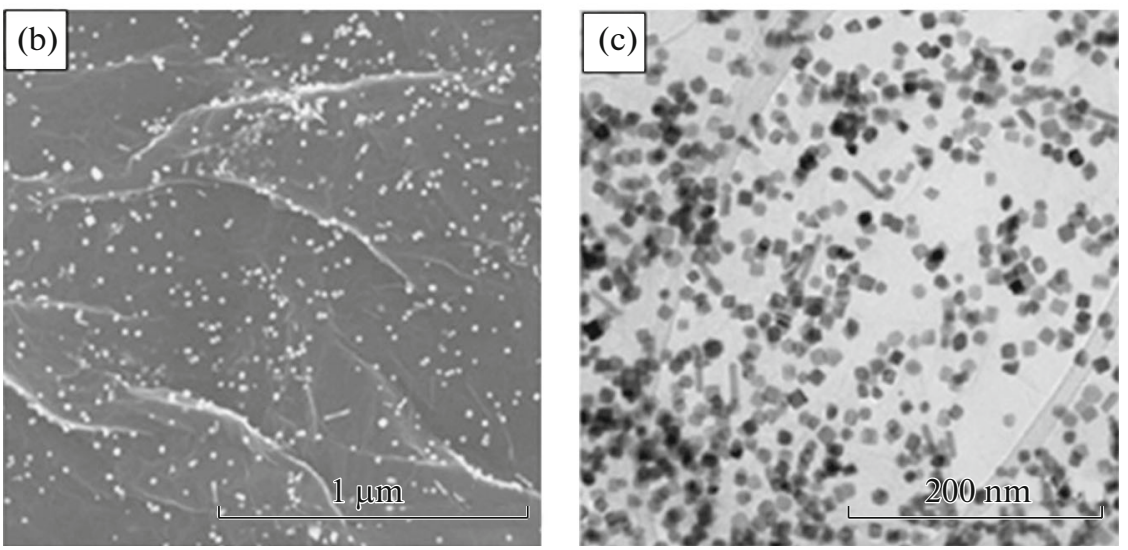

Fig. 32. (a) Scheme of preparation of a Pt-BG electrocatalyst; (b) SEM and (c) TEM images of the Pt-BG-3 electrocatalyst (4-4.7 at \% Pt) [160].

$\mathrm{N}$ and Fe. In addition to increasing their stability, the $\mathrm{Fe}-\mathrm{N}-\mathrm{C}$ functional groups act as additional sites active in the ORR, which makes it possible to reduce the Pt loading.

In [159], a simple and environmentally friendly method for doping graphene with boron was proposed, and it was also shown that it is the modified polyol method of catalyst synthesis that makes it possible to obtain a catalyst with high activity and optimal morphology. It was also possible to synthesize $\mathrm{Pt}$ nanoparticles with an almost zero degree of agglomeration by using B-doped RGO (Fig. 32). The particle size was in the range of $9-16 \mathrm{~nm}$ for the Pt-BG-3 sample with a sufficiently high Pt content (4-4.7 at \% Pt) [160].

The modification of carbon materials, such as activated carbon, carbon black, CNF, graphite, and graphene-like materials, with oxygen by using ozone treatment [161-163] for the controlled formation of oxygen-containing functional groups on their surface, is relatively poorly studied. The relative simplicity of the setup design, the simple principle of its operation, and its low cost are advantages of this method over, for example, liquid-phase oxidation or treatment with oxygen plasma. In addition, this approach is easily scalable for mass production and can be supplemented by such operations as raising the process temperature and adding steam or ultraviolet treatment [164] to increase the oxidation state. According to [165], the treatment of graphene-like materials with ozone made it possible to increase the specific surface area of expanded graphite and to form additional functional groups on its surface, while the $\mathrm{O} / \mathrm{C}$ ratio reached 0.2 when the process was carried out at room temperature. Ozonation at elevated temperatures (about $140^{\circ} \mathrm{C}$ ) causes partial decomposition of graphite, which is accompanied by the release of $\mathrm{CO}$ and $\mathrm{CO}_{2}$. On the other hand, single-layer and multilayer graphene-like plates subjected to ozone treatment undergo a change in their structure towards the amorphous state, according to the results published [164]. In [163], it was succeeded in achieving an $\mathrm{O} / \mathrm{C}$ value of 0.503 and increasing the number of carboxyl groups by an order of magnitude to more than $14 \%$ by ozonation of RGO 


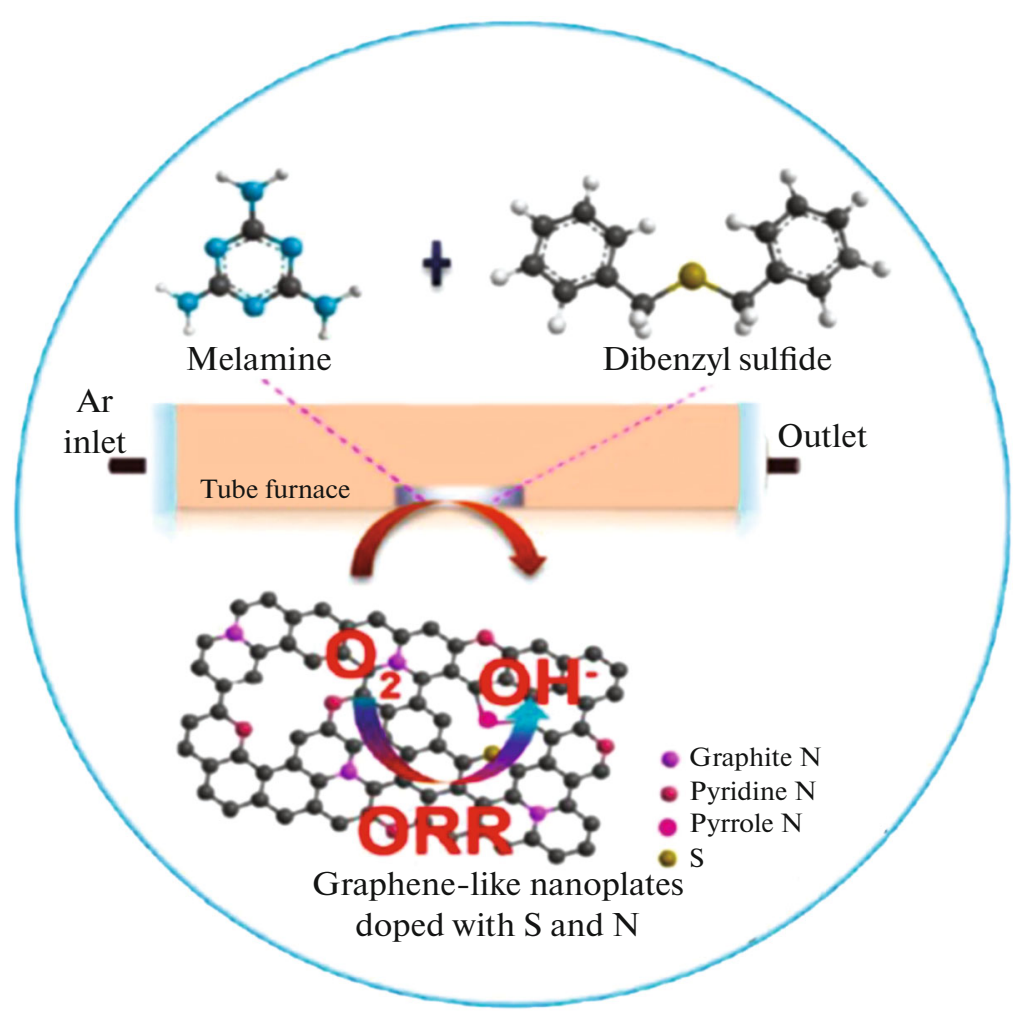

Fig. 33. (Color online) Schematic representation of the procedure of synthesis of an ORR electrocatalyst in the form of graphenelike plates doped with $\mathrm{S}$ and $\mathrm{N}$ [171].

nanosheets at $80^{\circ} \mathrm{C}$. In [166], graphite was preliminarily oxidized by an electrochemical method, exfoliated, and then used as a support for Pt nanoparticles. The obtained electrocatalyst demonstrated high activity in the ORR both in a study by the method of a rotating disk electrode and in the membrane-electrode unit of a FC. The appearance of defects and functional groups $(\mathrm{C}=\mathrm{O}$ and $\mathrm{OH})$ in graphite as a result of electrochemical oxidative treatment was confirmed by Raman and photoelectron spectroscopy methods. Experimental studies [167, 168] showed that the treatment of RGO with ozone leads to the formation of additional oxygen functional groups on its surface; however, ozone oxidizes the most chemically active surface regions, which could already act as nucleation centers for nanoparticles. Therefore, a substantial increase in the number of particle nucleation centers and a corresponding decrease in the size of $\mathrm{Pt}$ nanoparticles (and an increase in the catalyst EASA) were not observed. On the contrary, the modification of RGO with fluorine led to an increase in the mean size of Pt nanoparticles and a sharp decrease in the electrocatalyst EASA area, which is explained by the strong acceptor properties of fluorine and the low accessibility of the surface of the fluorinated support for sorption of the precursor.

Carbon materials doped with heteroatoms themselves are promising nonmetallic electrocatalysts that can be used in electrochemical storage and energy conversion applications [169-172]. Their operation mechanism is explained by the difference between the electronegativity of the doping heteroatoms and the carbon atoms of the support itself, which leads to a change in the distribution of the atomic charge/spin density on neighboring carbon atoms that act as active sites in the ORR [173]. Such a large difference in the electronegativity of atoms in the support matrix also enhances the interaction between metal nanoparticles (for example, $\mathrm{Pt}$ ) and the support, which contributes to an increase in the nanoparticle stability. For example, it was shown in [174] that electrodes based on $\mathrm{N}$-doped RGO demonstrated high activity, stability, and tolerance in the ORR. Moreover, the activity can be controlled by the concentration and configuration of $\mathrm{N}$ atoms. According to recent studies, $\mathrm{N}$ atoms in the forms pyridine and graphite are mainly responsible for the activity of nitrogen-doped carbon nanomaterials [175]. In [172], an electrocatalyst in the form of graphene-like plates simultaneously doped with $\mathrm{S}$ and $\mathrm{N}$ atoms (Fig. 33) showed higher activity in the ORR in comparison with monodoped counterparts and substantially higher stability as compared to the traditional ORR electrocatalyst, i.e., Pt/C, in both acidic and alkaline media. The high activity in the ORR is caused by the high content of nitrogen in the forms of graphite and pyridine; however, $\mathrm{S}$ atoms enable polar- 
ization of neighboring $\mathrm{C}$ and $\mathrm{N}$ atoms, which leads to stretching and the appearance of defects in the carbon cage, ultimately contributing to the chemisorption of oxygen [176].

$\mathrm{P}$ atoms are too large to be embedded in the graphite plane and can effectively occupy only edge defects. $P$ active sites are most active in the case of an unoxidized electrocatalyst and can be easily oxidized by oxygen-containing particles and lose their activity. However, the oxidized $\mathrm{P}$ active site bonded to $\mathrm{N}$ stabilizes the graphite state of $\mathrm{N}$ and activates the neighboring $\mathrm{C}$ site in the reaction of oxygen evolution [170].

Despite the rather high activity values achieved under laboratory conditions, nonplatinum electrocatalysts have not yet demonstrated a sufficiently high proven service life in fuel cells to compete with Pt-based electrocatalysts.

\section{CONCLUSIONS}

This review shows that the exploration and study of the properties of graphene and graphene-like materials (GO, RGO, CNT, CNF, etc.), as well as the development of available methods for the synthesis of these materials, with the aim of their wide application in efficient systems for purification and reversible storage of hydrogen and in fuel cells as electrocatalyst supports are of great interest.

The results of theoretical and experimental studies confirm the possibility of creating efficient systems for reversible hydrogen storage on the basis of graphene materials. The developments are carried out in several directions. The possibility of increasing the sorption capacity and improving the kinetics of sorption/desorption of hydrogen by changing the curvature of the graphene surface, increasing the distance between layers, and creating 3D framework systems based on graphene or RGO is shown. The functionalization of graphene with heteroatoms (surface decoration or doping by substitution of carbon atoms) is another important direction of development. Transition metal atoms on the graphene surface act as catalytic sites for dissociative chemisorption of hydrogen, which leads to the appearance of a spillover effect that increases the sorption efficiency. The combined decoration and doping, especially when nitrogen is used for doping and Pt and Pd metals for decorating, is apparently the most promising approach. The development of composites from nanostructured hydrides wrapped in graphene is also of interest. For example, a composite that contains $2 \mathrm{LiBH}_{4}-\mathrm{MgH}_{2}$ nanoparticles uniformly distributed over flexible, but strong graphene substrates has a sorption capacity of $9.1 \mathrm{wt} \%$ and shows good cycling stability.

The development of chemically and heat-resistant graphene-based membrane materials that offer high permeability and selectivity can lead to significant progress in membrane technologies for hydrogen con- centration and its purification from impurities. The formation of the required pores in the graphene plane, the design of channels in graphene layers (with use of graphene oxide), and the creation of nanocomposite and hybrid membranes containing graphene or graphene oxide plates and an inorganic membrane material are main areas of work are main lines of developments. To improve the characteristics of polymer membranes that are mostly used in industry today, additives of graphene materials are proposed. For example, polymer membranes with additives of 0.2 wt $\%$ RGO demonstrated extremely high $\mathrm{H}_{2} / \mathrm{CH}_{4}$ selectivity. New membranes are promising for hydrogen purification in the processes of its production from natural gas.

The use of RGO as a support for Pt nanoparticles makes it possible to improve the transport characteristics of the electrocatalytic layer in an PEMFC, to increase its stability (as a result of both the higher stability of the support and the specific interactions between nanoparticles and the support), and to increase the activity of the electrocatalyst in the ORR (which helps to reduce the Pt content). The problem of restacking (agglomeration) of flat particles (sheets) of graphene-like materials can be solved by incorporating (intercalating) functional additives (for example, carbon black particles or nanotubes between sheet particles of RGO, including those with already deposited $\mathrm{Pt}$ nanoparticles), introducing functional groups, or applying metal nanoparticles that prevent agglomeration under the action of van der Waals forces on their surface. Graphene-like materials themselves can act as functional additives in the electrocatalytic layer based on a traditional catalyst, which makes it possible to increase the efficiency of the fuel cell in the region of high current densities by improving the transport characteristics of the layer (increasing porosity, accelerating oxygen diffusion, etc.), and increasing the electrical conductivity and the degree of utilization of the noble metal. Graphene-like materials can be doped with heteroatoms ( $\mathrm{N}, \mathrm{O}, \mathrm{B}, \mathrm{P}$, and $\mathrm{S}$ ) by various methods in one or several steps, which allows one to influence, to a certain extent, the electrocatalytic properties of RGO itself or Pt nanoparticles on its surface, as well as their morphology. The most promising methods for modifying the surface of graphene-like materials are plasma methods because they make it possible to avoid the use of high temperatures and solvents, and prevent the contaminations of the final product, which are associated with these factors.

\section{FUNDING}

This study was supported by the Russian Foundation for Basic Research within project no. 18-53-53025. 


\section{REFERENCES}

1. M. S. Dresselhaus and P. T. Araujo, ACS Nano 4, 6297 (2010). https://doi.org/10.1021/nn1029789

2. A. L. Ivanovskii, Russ. Chem. Rev. 81, 571 (2012). https://doi.org/10.1070/RC2012v081n07ABEH004302

3. S. P. Gubin and S. V. Tkachev, Graphene and Related Carbon Nanoforms (Librokom, Moscow, 2012) [in Russian].

4. O. K. Alekseeva, S. I. Kozlov, R. O. Samsonov, and V. N. Fateev, Transp. Al'tern. Toplive, No. 4 (10), 68 (2009).

5. O. K. Alekseeva, S. I. Kozlov, R. O. Samsonov, and V. N. Fateev, Transp. Al'tern. Toplive, No. 5 (11), 72 (2009).

6. V. N. Fateev, O. K. Alekseeva, S. V. Korobtsev, et al., Chem. Probl., No. 4 (16), 453 (2018).

7. Yu. S. Nechaev and O. K. Alekseeva, Russ. Chem. Rev. 73, 1211 (2004).

8. Yu. S. Nechaev, O. K. Alexeeva, and A. Öchsner, J. Nanosci. Nanotechnol. 9, 3949 (2009). https://doi.org/10.1166/jnn.2009.NS95

9. X. Yu, Z. Tang, D. Sun, et al., Prog. Mater. Sci. 88, 1 (2017). https://doi.org/10.1016/j.pmatsci.2017.03.001

10. M. D. Stoller, S. Park, Y. Zhu, et al., Nano Lett. 8, 3498 (2008). https://doi.org/10.1021/nl802558y

11. A. Klechikov, G. Mercier, T. Sharifi, et al., Chem. Commun. 51, 15280 (2015). https://doi.org/10.1039/C5CC05474E

12. L. Bellucci and V. Tozzini, Molecules 25, 339 (2020). https://doi.org/10.3390/molecules25020339

13. V. Tozzini and V. Pellegrini, Phys. Chem. Chem. Phys. 15, 80 (2013). https://doi.org/10.1039/C2CP42538F

14. V. Jain and B. Kandasubramanian, J. Mater. Sci. 55, 1865 (2019). https://doi.org/10.1007/s10853-019-04150-y

15. S. Patchkovskii, J. S. Tse, S. N. Yurchenko, et al., Proc. Natl. Acad. Sci. U. S. A. 102, 10439 (2005). https://doi.org/10.1073/pnas.0501030102

16. M. S. L. Hudson, H. Raghubanshi, S. Awasthi, et al., Int. J. Hydrogen Energy 39, 8311 (2014). https://doi.org/10.1016/j.ijhydene.2014.03.118

17. E. Boateng and A. Chen, Mater. Today Adv. 6, 100022 (2020). https://doi.org/10.1016/j.mtadv.2019.100022

18. K. S. Subrahmanyam, S. R. C. Vivekchand, A. Govindaraj, and C. N. R. Rao, J. Mater. Chem. 18, 1517 (2008). https://doi.org/10.1039/b716536f

19. P. K. Chauhan, V. Vidhukiran, R. Sujith, and R. Parameshwaran, Mater. Res. Express 6, 105617 (2019). https://doi.org/10.1088/2053-1591/ab3cdc

20. A. V. Golubeva and D. I. Cherkez, Vopr. At. Nauki Tekh., Ser.: Termoyad. Sintez 41 (4), 26 (2018). https://doi.org/10.21517/0202-3822-2018-41-4-26-37
21. Z. Waqar, J. Mater. Sci. 42, 1169 (2007). https://doi.org/10.1007/s10853-006-1453-1

22. Y. S. Nechaev and T. N. Veziroglu, Adv. Mater. Phys. Chem. 3, 255 (2013). https://doi.org/10.4236/ampc.2013.35037

23. M. M. Slepchenkov, P. V. Barkov, and O. E. Glukhova, Crystals 8, 161 (2018). https://doi.org/10.3390/cryst8040161

24. N. G. Boddeti, S. P. Koenig, R. Long, et al., J. Appl. Mech. 80, 040909 (2013). https://doi.org/10.1115/1.4024255

25. M. H. F. Sluiter and Y. Kawazoe, Phys. Rev. B 68, 085410 (2003). https://doi.org/10.1103/PhysRevB.68.085410

26. J. O. Sofo, A. S. Chaudhari, and G. D. Barber, Phys. Rev. B 75, 153401 (2007). https://doi.org/10.1103/PhysRevB.75.153401

27. D. C. Elias, R. R. Nair, T. M. G. Mohiuddin, et al., Science (Washington, DC, U. S.) 323, 610 (2009). https://doi.org/10.1126/science.1167130

28. V. D. Camiola, R. Farchioni, T. Cavallucci, et al., Front. Mater. 2, 1 (2015). https://doi.org/10.3389/fmats.2015.00003

29. V. Tozzini and V. Pellegrini, J. Phys. Chem. C 115, 25523 (2011). https://doi.org/10.1021/jp208262r

30. S. Goler, C. Coletti, V. Tozzini, et al., J. Phys. Chem. C 117, 11506 (2013). https://doi.org/10.1021/jp4017536

31. S. Deng and V. Berry, Mater. Today 19, 197 (2016). https://doi.org/10.1016/j.mattod.2015.10.002

32. H. McKay, D. J. Wales, S. J. Jenkins, et al., Phys. Rev. B 81, 075425 (2010). https://doi.org/10.1103/PhysRevB.81.075425

33. P. Z. Sun, Q. Yang, W. J. Kuang, et al., Nature (London, U.K.) 579, 229 (2020). https://doi.org/10.1038/s41586-020-2070-X

34. I. A. Baburin, A. Klechikov, G. Mercier, et al., Int. J. Hydrogen Energy 40, 6594 (2015). https://doi.org/10.1016/j.ijhydene.2015.03.139

35. A. Pedrielli, S. Taioli, G. Garberoglio, and N. M. Pugno, Microporous Mesoporous Mater. 257, 222 (2018). https://doi.org/10.1016/j.micromeso.2017.08.034

36. G. K. Dimitrakakis, E. Tylianakis, and G. E. Froudakis, Nano Lett. 8, 3166 (2008). https://doi.org/10.1021/nl801417w

37. E. Klontzas, E. Tylianakis, V. Varshney, et al., Sci. Rep. 9, 13676 (2019). https://doi.org/10.1038/s41598-019-50037-y

38. X. Wu and X. C. Zeng, Nano Lett. 9, 250 (2009). https://doi.org/10.1021/n1802832m

39. K. Xia, H. Zhan, and Y. Gu, Proc. IUTAM 21, 94 (2017). https://doi.org/10.1016/j.piutam.2017.03.042

40. H. G. Shiraz and O. Tavakoli, Renewable Sustainable Energy Rev. 74, 104 (2017). https://doi.org/10.1016/j.rser.2017.02.052

41. F. Bonaccorso, L. Colombo, G. Yu, et al., Science (Washington, DC, U. S.) 347, 1246501 (2015). https://doi.org/10.1126/science.1246501 
42. M. Mohan, V. K. Sharma, E. A. Kumar, and V. Gayathri, Energy Storage 1, 35 (2019). https://doi.org/10.1002/est2.35

43. K. Spyrou, D. Gournis, and P. Rudolf, ECS J. Solid State Sci. Technol. 2, M3160 (2013). https://doi.org/10.1149/2.018310jss

44. X. F. Zhou, H. Y. Fang, and C. M. Tang, Acta Phys. Sin. 68, 053601 (2019). https://doi.org/10.7498/aps.68.20181497

45. H. Tachikawa and T. Iyama, J. Phys. Chem. C 123, 8709 (2019). https://doi.org/10.1021/acs.jpcc.9b01152

46. C. C. Huang, N. W. Pu, C. A. Wang, et al., Sep. Purif. Technol. 82, 210 (2011). https://doi.org/10.1016/j.seppur.2011.09.020

47. S. Lamichhane, N. Pantha, and N. Adhikari, Bibechana 11, 113 (2014). https://doi.org/10.3126/bibechana.v11i0.10389

48. A. Ariharan, B. Viswanathan, and V. Nandhakumar, Graphene 6, 41 (2017). https://doi.org/10.4236/graphene.2017.62004

49. A. Ariharan, B. Viswanathan, and V. Nandhakumar, Graphene 5, 39 (2016). https://doi.org/10.4236/graphene.2016.52005

50. E. H. O. Gueye, A. N. Dione, A. Dioum, et al., Am. J. Nanomater. 7, 30 (2019). https://doi.org/10.12691/ajn-7-1-4

51. B. P. Vinayan, K. Sethupathi, and S. Ramaprabhu, J. Nanosci. Nanotechnol. 12, 6608 (2012). https://doi.org/10.1166/jnn.2012.4539

52. Y. S. Nechaev, V. P. Filippova, A. A. Tomchuk, et al., Nanosyst.: Phys. Chem. Math. 7, 204 (2016). https://doi.org/10.17586/2220-8054-2016-7-1-204-209

53. H. Lee, J. Ihm, M. L. Cohen, and S. G. Louie, Nano Lett. 10, 793 (2010). https://doi.org/10.1021/n1902822s

54. P. Divya and S. Ramaprabhu, Phys. Chem. Chem. Phys. 16, 26725 (2014). https://doi.org/10.1039/C4CP04214J

55. C. Zhou and J. A. Szpunar, ACS Appl. Mater. Interfaces 8, 25933 (2016). https://doi.org/10.1021/acsami.6b07122

56. H. Wang, T. Maiyalagan, and X. Wang, ACS Catal. 2, 781 (2012). https://doi.org/10.1021/cs200652y

57. M. Scardamaglia and C. Bittencourt, Beilstein J. Nanotechnol. 9, 2015 (2018). https://doi.org/10.3762/bjnano.9.191

58. R. Paul, Q. Dai, C. Hu, and L. Dai, Carbon Energy 1, 19 (2019). https://doi.org/10.1002/cey2.5

59. K. Gao, B. Wang, L. Tao, et al., Adv. Mater. 31, 1805121 (2019). https://doi.org/10.1002/adma.201805121

60. A. S. Pushkarev, O. K. Alekseeva, I. V. Pushkareva, et al., Nanotechnol. Russ. 15 (2020, in press).

61. G. Xia, Y. Tan, F. Wu, et al., Nano Energy 26, 488 (2016). https://doi.org/10.1016/j.nanoen.2016.06.016
62. S. I. Kozlov and V. N. Fateev, Hydrogen Energy: Current State, Problems, Prospects (Gazprom VNIIGAZ, Moscow, 2009) [in Russian].

63. E. Yu. Mironova, M. M. Ermilova, N. V. Orekhova, A. S. Tolkacheva, S. N. Shkerin and A. B. Yaroslavtsev, Nanotechnol. Russ. 12, 597 (2017).

64. N. W. Ockwig and T. M. Nenoff, Chem. Rev. 107, 4078 (2007). https://doi.org/10.1021/cr0501792

65. X. Y. Chen, N. Tien-Binh, A. Romero, et al., J. Membr. Sci. Res. 6, 58 (2020). https://doi.org/10.22079/JMSR.2019.100069.1244

66. S. K. Alen, S. Nam, and S. A. Dastgheib, Int. J. Mol. Sci. 20, 5609 (2019). https://doi.org/10.3390/ijms20225609

67. H. W. Yoon, Y. H. Cho, and H. B. Park, Philos. Trans. R. Soc. A 374, 20150024 (2016). https://doi.org/10.1098/rsta.2015.0024

68. O. K. Alekseeva and D. M. Amirkhanov, Ros. Khim. Zh. 48 (5), 82 (2004).

69. D. M. Amirkhanov, O. K. Alekseeva, A. A. Kotenko, et al., Membrany, No. 4 (32), 19 (2006).

70. O. K. Alekseeva, A. A. Kotenko, and M. M. Chelyak, Membrany, No. 4 (36), 3 (2007).

71. O. K. Alexeeva, Y. S. Nechaev, B. L. Shapir, and A. Öchsner, Int. Sci. J. Altern. Energy Ecol., No. 1 (69), 131 (2009).

72. J. Shen, M. Zhang, G. Liu, et al., AIChE J. 62, 2843 (2016). https://doi.org/10.1002/aic.15260

73. Z. Kang, S. Wang, L. Fan, et al., Commun. Chem. 1, 3 (2018). https://doi.org/10.1038/s42004-017-0002-y

74. T. Hyun, J. Jeong, A. Chae, et al., BMC Chem. Eng. 1, 12 (2019). https://doi.org/10.1186/s42480-019-0012-X

75. S. Kim, H. Wang, and Y. M. Lee, Angew. Chem. Int. Ed. 58, 17512 (2019). https://doi.org/10.1002/anie.201814349

76. M. R. A. Hamid and H. K. Jeong, Korean J. Chem. Eng. 35, 1577 (2018). https://doi.org/10.1007/s11814-018-0081-1

77. C. Sun, X. Zheng, and B. Bai, Chem. Eng. Sci. 208, 115141 (2019). https://doi.org/10.1016/j.ces.2019.07.059

78. O. K. Alekseeva, Voda Mag., No. 6 (82), 30 (2014).

79. L. Huang and H. Lin, Membranes 8, 100 (2018). https://doi.org/10.3390/membranes 8040100

80. S. C. O’Hern, M. S. H. Boutilier, J. C. Idrobo, et al., Nano Lett. 14, 1234 (2014). https://doi.org/10.1021/nl404118f

81. K. Celebi, J. Buchheim, R. M. Wyss, et al., Science (Washington, DC, U. S.) 344, 289 (2014). https://doi.org/10.1126/science.1249097

82. T. Gilboa, A. Zrehen, A. Girsault, and A. Meller, Sci. Rep. 8, 9765 (2018). https://doi.org/10.1038/s41598-018-28136-z

83. S. Huang, M. Dakhchoune, W. Luo, et al., Nat. Commun. 9, 2632 (2018). https://doi.org/10.1038/s41467-018-04904-3 
84. J. Zhao, G. He, S. Huang, et al., Sci. Adv. 5, 1851 (2019). https://doi.org/10.1126/sciadv.aav1851

85. S. Wei, S. Zhou, Z. Wu, et al., Appl. Surf. Sci. 441, 631 (2018). https://doi.org/10.1016/j.apsusc.2018.02.111

86. H. W. Kim, H. W. Yoon, S. M. Yoon, et al., Science (Washington, DC, U. S.) 342, 91 (2013). https://doi.org/10.1126/science.1236098

87. D. Bouša, K. Friess, K. Pilnáček, et al., Chem.-Eur. J. 23, 11416 (2017). https://doi.org/10.1002/chem.201702233

88. H. Zheng, L. Zhu, D. He, et al., Int. J. Hydrogen Energy 42, 30653 (2017). https://doi.org/10.1016/j.ijhydene.2017.10.134

89. A. Ibrahim and Y. S. Lin, J. Membr. Sci. 550, 238 (2018). https://doi.org/10.1016/j.memsci.2017.12.081

90. A. F. M. Ibrahim and Y. S. Lin, Chem. Eng. Sci. 190, 312 (2018). https://doi.org/10.1016/j.ces.2018.06.031

91. J. Lyu, X. Wen, U. Kumar, et al., RSC Adv. 8, 23130 (2018). https://doi.org/10.1039/C8RA03156H

92. A. F. M. Ibrahim, F. Banihashemi, and Y. S. Lin, Chem. Commun. 55, 3077 (2019). https://doi.org/10.1039/C8CC10283J

93. Q. Liu, K. M. Gupta, Q. Xu, et al., Sep. Purif. Technol. 209, 419 (2019). https://doi.org/10.1016/j.seppur.2018.07.044

94. R. Zeynali, K. Ghasemzadeh, A. B. Sarand, et al., Catal. Today 330, 16 (2019). https://doi.org/10.1016/j.cattod.2018.05.047

95. M. Ostwal, D. B. Shinde, X. Wang, et al., J. Membr. Sci. 550, 145 (2018). https://doi.org/10.1016/j.memsci.2017.12.063

96. V. Palmieri and M. Papi, Nano Today 33, 100883 (2020). https://doi.org/10.1016/j.nantod.2020.100883

97. H. Zhong, Z. Zhu, J. Lin, et al., ACS Nano 14, 6213 (2020). https://doi.org/10.1021/acsnano.0c02250

98. W. R. W. Daud, R. E. Rosli, E. H. Majlan, et al., Renewable Energy 113, 620 (2017). https://doi.org/10.1016/j.renene.2017.06.027

99. M. Bodner, J. Senn, and V. Hacker, Fuel Cells and Hydrogen: From Fundamentals to Applied Research (Elsevier, Amsterdam, 2018). https://doi.org/10.1016/B978-0-12-811459-9.00007-4

100. L. Dai, D. W. Chang, J. B. Baek, and W. Lu, Small 8, 1130 (2012). https://doi.org/10.1002/smll.201101594

101. P. Trogadas, T. F. Fuller, and P. Strasser, Carbon (N. Y.) 75, 5 (2014). https://doi.org/10.1016/j.carbon.2014.04.005

102. S. Sharma and B. G. Pollet, J. Power Sources 208, 96 (2012). https://doi.org/10.1016/j.jpowsour.2012.02.011

103. E. Antolini, Appl. Catal. B 88, 1 (2009). https://doi.org/10.1016/j.apcatb.2008.09.030
104. E. Antolini, Appl. Catal. B 123-124, 52 (2012). https://doi.org/10.1016/j.apcatb.2012.04.022

105. M. Liu, R. Zhang, and W. Chen, Chem. Rev. 114, 5117 (2014). https://doi.org/10.1021/cr400523y

106. L. Du, Y. Shao, J. Sun, et al., Nano Energy 29, 314 (2016). https://doi.org/10.1016/j.nanoen.2016.03.016

107. R. P. Pandey, G. Shukla, M. Manohar, and V. K. Shahi, Adv. Colloid Interface Sci. 240, 15 (2017). https://doi.org/10.1016/j.cis.2016.12.003

108. S. Sui, X. Wang, X. Zhou, et al., J. Mater. Chem. A 5, 1808 (2017). https://doi.org/10.1039/C6TA08580F

109. Y. Li, L. Tang, and J. Li, Electrochem. Commun. 11, 846 (2009). https://doi.org/10.1016/j.elecom.2009.02.009

110. S. H. Hsieh, M. C. Hsu, W. L. Liu, and W. J. Chen, Appl. Surf. Sci. 277, 223 (2013). https://doi.org/10.1016/j.apsusc.2013.04.029

111. Y. Xin, J. Liu, Y. Zhou, et al., J. Power Sources 196, 1012 (2011). https://doi.org/10.1016/j.jpowsour.2010.08.051

112. Y. Liang, D. Wu, X. Feng, and K. Müllen, Adv. Mater. 21, 1679 (2009). https://doi.org/10.1002/adma.200803160

113. H. Wang, J. Du, Z. Yao, et al., Colloids Surf., A 436 , 57 (2013). https://doi.org/10.1016/j.colsurfa.2013.06.020

114. Z. Yao, M. Zhu, F. Jiang, et al., J. Mater. Chem. 22, 13707 (2012). https://doi.org/10.1039/c2jm31683h

115. Z. Yao, R. Yue, C. Zhai, et al., Int. J. Hydrogen Energy 38, 6368 (2013). https://doi.org/10.1016/j.ijhydene.2013.02.140

116. M. Lei, C. Liang, Y. J. Wang, et al., Electrochim. Acta 113, 366 (2013). https://doi.org/10.1016/j.electacta.2013.09.119

117. S. Park, Y. Shao, H. Wan, et al., Electrochem. Commun. 13, 258 (2011). https://doi.org/10.1016/j.elecom.2010.12.028

118. K. Cheng, D. He, T. Peng, et al., Electrochim. Acta 132, 356 (2014). https://doi.org/10.1016/j.electacta.2014.03.181

119. I. E. Baranov, V. I. Porembskii, E. K. Lyutikova, et al., Chem. Probl., No. 4 (17), 489 (2019). https://doi.org/10.32737/2221-8688-2019-4-489-499

120. L. I. Şanli, V. Bayram, B. Yarar, et al., Int. J. Hydrogen Energy 41, 3414 (2016). https://doi.org/10.1016/j.ijhydene.2015.12.166

121. E. Daş, S. Alkan Gürsel, L. Işikel Şanli, and A. Bayrakçeken Yurtcan, Int. J. Hydrogen Energy 41, 9755 (2016). https://doi.org/10.1016/j.ijhydene.2016.01.111

122. S. Hussain, H. Erikson, N. Kongi, et al., ChemElectroChem 5, 2902 (2018). https://doi.org/10.1002/celc.201800582

123. Y. Devrim, E. D. Arica, and A. Albostan, Int. J. Hydrogen Energy 43, 11820 (2018). https://doi.org/10.1016/j.ijhydene.2018.03.047 
124. G. U. Alpaydin, Y. Devrim, and C. O. Colpan, Int. J. Energy Res. 43, 3578 (2019). https://doi.org/10.1002/er.4504

125. L. Pak Hoe, M. Boaventura, T. Lagarteira, et al., Int. J. Hydrogen Energy 43, 16998 (2018). https://doi.org/10.1016/j.ijhydene.2018.05.147

126. A. S. Pushkarev, M. A. Solovyev, S. A. Grigoriev, et al., Int. J. Hydrogen Energy 45, 26206 (2020). https://doi.org/10.1016/j.ijhydene.2020.02.098

127. Y. Z. Voloshin, N. V. Chornenka, O. A. Varzatskii, et al., Electrochim. Acta 269, 590 (2018). https://doi.org/10.1016/j.electacta.2018.03.030

128. Y. Z. Voloshin, N. V. Chornenka, A. S. Belov, et al., J. Electrochem. Soc. 166, H598 (2019). https://doi.org/10.1149/2.0391913jes

129. S. Dey, B. Mondal, S. Chatterjee, et al., Nat. Rev. Chem. 1, 0098 (2017). https://doi.org/10.1038/s41570-017-0098

130. L. I. Şanlı, B. Yarar, V. Bayram, and S. A. Gürsel, J. Mater. Sci. 52, 2091 (2017). https://doi.org/10.1007/s10853-016-0497-0

131. M. S. Yılmaz, B. Y. Kaplan, Ö. Metin, and S. A. Gürsel, Mater. Des. 151, 29 (2018). https://doi.org/10.1016/j.matdes.2018.04.041

132. L. I. Şanlı, V. Bayram, S. Ghobadi, et al., Int. J. Hydrogen Energy 42, 1085 (2017). https://doi.org/10.1016/j.ijhydene.2016.08.210

133. A. B. Yurtcan and E. Daş, Int. J. Hydrogen Energy 43, 18691 (2018). https://doi.org/10.1016/j.ijhydene.2018.06.186

134. H. N. Yang, D. C. Lee, K. W. Park, and W. J. Kim, Energy 89, 500 (2015). https://doi.org/10.1016/j.energy.2015.06.019

135. Y. S. Yun, D. Kim, Y. Tak, and H. J. Jin, Synth. Met. 161, 2460 (2011). https://doi.org/10.1016/j.synthmet.2011.09.030

136. Z. Liu, A. A. Abdelhafiz, Y. Jiang, et al., Mater. Chem. Phys. 225, 371 (2019). https://doi.org/10.1016/j.matchemphys.2018.12.100

137. N. V. Glebova, A. A. Nechitailov, and V. N. Gurin, Tech. Phys. Lett. 37, 661 (2011).

138. A. A. Nechitailov, N. V. Glebova, D. V. Koshkina, A. A. Tomasov, N. K. Zelenina, and E. E. Terukova, Tech. Phys. Lett. 39, 762 (2013).

139. A. A. Nechitailov and N. V. Glebova, Russ. J. Electrochem. 50, 751 (2014).

140. J. Y. Lee, J. J. Lee, H. R. Rhim, et al., Adv. Mater. Res. 123-125, 1107 (2010). https://doi.org/10.4028/www.scientific.net/AMR.123125.1107

141. A. I. Finaenov, I. E. Shpak, A. V. Afonina, et al., Vestn. SGTU, No. 4 (68), 107 (2012).

142. A. V. Yakovlev, A. I. Finaenov, S. L. Zabud'kov, and E. V. Yakovleva, Russ. J. Appl. Chem. 79, 1741 (2006).

143. B. K. Kakati, A. Ghosh, and A. Verma, Int. J. Hydrogen Energy 38, 9362 (2013). https://doi.org/10.1016/j.ijhydene.2012.11.075

144. C. C. Sung, C. Y. Liu, and C. C. J. Cheng, Int. J. Hydrogen Energy 39, 11706 (2014).

https://doi.org/10.1016/j.ijhydene.2014.05.154
145. A. S. Pushkarev, I. V. Pushkareva, S. A. Grigoriev, et al., Int. J. Hydrogen Energy 40, 14492 (2015). https://doi.org/10.1016/j.ijhydene.2015.05.093

146. S. A. Grigor'ev, A. S. Pushkarev, V. N. Kalinichenko, I. V. Pushkareva, M. Yu. Presnyakov, and V. N. Fateev, Kinet. Catal. 56, 689 (2015).

147. I. E. Baranov, I. I. Nikolaev, A. S. Pushkarev, et al., Int. J. Electrochem. Sci. 13, 8673 (2018). https://doi.org/10.20964/2018.09.48

148. N. V. Glebova, A. O. Krasnova, and A. A. Nechitailov, Russ. J. Appl. Chem. 91, 1262 (2018).

149. A. O. Krasnova, N. V. Glebova, D. V. Zhilina, and A. A. Nechitailov, Russ. J. Appl. Chem. 90, 361 (2017). https://doi.org/10.1134/S1070427217030065

150. A. A. Ignatova and O. V. Yarmolenko, Al'tern. Energet. Ekol. 172-173 (8-9), 112 (2015). https://doi.org/10.15518/isjaee.2015.08-09.014

151. D. R. Dreyer, S. Park, C. W. Bielawski, and R. S. Ruoff, Chem. Soc. Rev. 39, 228 (2010). https://doi.org/10.1039/B917103G

152. X. Wang, G. Sun, P. Routh, et al., Chem. Soc. Rev. 43, 7067 (2014). https://doi.org/10.1039/C4CS00141A

153. M. Vikkisk, I. Kruusenberg, U. Joost, et al., Appl. Catal. B 147, 369 (2014). https://doi.org/10.1016/j.apcatb.2013.09.011

154. U. N. Maiti, W. J. Lee, J. M. Lee, et al., Adv. Mater. 26, 40 (2014). https://doi.org/10.1002/adma.201303265

155. M. V. Martínez-Huerta, and M. J. Lázaro, Catal. Today 285, 3 (2017). https://doi.org/10.1016/j.cattod.2017.02.015

156. A. Heydari and H. Gharibi, J. Power Sources 325, 808 (2016). https://doi.org/10.1016/j.jpowsour.2016.06.039

157. Z. Li, Q. Gao, H. Zhang, et al., Sci. Rep. 7, 43352 (2017). https://doi.org/10.1038/srep43352

158. J. Kim, C. Kim, I. Y. Jeon, et al., ChemElectroChem 5, 2857 (2018). https://doi.org/10.1002/celc.201800674

159. A. Pullamsetty, M. Subbiah, and R. Sundara, Int. J. Hydrogen Energy 40, 10251 (2015). https://doi.org/10.1016/j.ijhydene.2015.06.020

160. D. Lim, Y. Shim, J. Oh, et al., J. Solid State Chem. 271, 168 (2019). https://doi.org/10.1016/j.jssc.2018.12.058

161. S. D. Razumovskii, V. N. Gorshenev, A. L. Kovarskii, et al., Fullerenes, Nanotubes Carbon Nanostruct. 15, 53 (2007). https://doi.org/10.1080/15363830600812423

162. P. M. Álvarez, J. F. García-Araya, F. J. Beltrán, et al., J. Colloid Interface Sci. 283, 503 (2005). https://doi.org/10.1016/j.jcis.2004.09.014

163. Z. Xu, M. Yue, L. Chen, et al., Chem. Eng. J. 240, 187 (2014). https://doi.org/10.1016/j.cej.2013.11.045

164. H. Tao, J. Moser, F. Alzina, et al., J. Phys. Chem. C 115, 18257 (2011). https://doi.org/10.1021/jp2050756 
165. P. Krawczyk, Chem. Eng. J. 172, 1096 (2011). https://doi.org/10.1016/j.cej.2011.06.005

166. E. Teran-Salgado, D. Bahena-Uribe, P. A. MárquezAguilar, et al., Electrochim. Acta 298, 172 (2019). https://doi.org/10.1016/j.electacta.2018.12.057

167. S. A. Grigoriev, V. N. Fateev, A. S. Pushkarev, et al., Materials 11, 1405 (2018).

https://doi.org/10.3390/ma11081405

168. I. V. Pushkareva, "Development and research of electrocatalytic materials for fuel cells with solid polymer electrolyte," Cand. Sci. (Tech. Sci.) Dissertation (NRU "MPEI", Moscow, 2019).

169. J. Gaidukevič, J. Razumienè, I. Šakinyt?de, et al., Carbon (N. Y.) 118, 156 (2017).

https://doi.org/10.1016/j.carbon.2017.03.049

170. G. L. Chai, K. Qiu, M. Qiao, et al., Energy Environ. Sci. 10, 1186 (2017). https://doi.org/10.1039/C6EE03446B
171. J. Zhang, J. Wang, Z. Wu, et al., Catalysts 8, 475 (2018). https://doi.org/10.3390/catal8100475

172. J. Li, Y. Zhang, X. Zhang, et al., ACS Appl. Mater. Interfaces $\mathbf{9}, 398$ (2017). https://doi.org/10.1021/acsami.6b12547

173. K. Gong, F. Du, Z. Xia, et al., Science (Washington, DC, U. S.) 323, 760 (2009). https://doi.org/10.1126/science.1168049

174. J. Wu, L. Ma, R. M. Yadav, et al., ACS Appl. Mater. Interfaces 7, 14763 (2015).

https://doi.org/10.1021/acsami.5b02902

175. Z. Wu, M. Song, J. Wang, and X. Liu, Catalysts 8, 196 (2018). https://doi.org/10.3390/catal8050196

176. D. W. Wang and D. Su, Energy Environ. Sci. 7, 576 (2014). https://doi.org/10.1039/c3ee43463j

Translated by $O$. Kadkin 